University of Nebraska - Lincoln

DigitalCommons@University of Nebraska - Lincoln

U.S. Department of Veterans Affairs Staff

Publications

U.S. Department of Veterans Affairs

2012

\title{
Non-muscle myosin IIA transports a Golgi glycosyltransferase to the endoplasmic reticulum by binding to its cytoplasmic tail
}

\author{
Armen Petrosyan \\ Omaha Western lowa Health System \\ Mohamed F. Ali \\ Omaha Western lowa Health System \\ Shailendra Kumar Verma \\ University of Nebraska Medical Center \\ Helen Cheng \\ University of Nebraska Medical Center \\ Pi-Wan Cheng \\ University of Nebraska Medical Center, pcheng@unmc.edu
}

Follow this and additional works at: https://digitalcommons.unl.edu/veterans

Petrosyan, Armen; Ali, Mohamed F.; Verma, Shailendra Kumar; Cheng, Helen; and Cheng, Pi-Wan, "Nonmuscle myosin IIA transports a Golgi glycosyltransferase to the endoplasmic reticulum by binding to its cytoplasmic tail" (2012). U.S. Department of Veterans Affairs Staff Publications. 64.

https://digitalcommons.unl.edu/veterans/64

This Article is brought to you for free and open access by the U.S. Department of Veterans Affairs at DigitalCommons@University of Nebraska - Lincoln. It has been accepted for inclusion in U.S. Department of Veterans Affairs Staff Publications by an authorized administrator of DigitalCommons@University of Nebraska - Lincoln. 


\title{
Non-muscle myosin IIA transports a Golgi glycosyltransferase to the endoplasmic reticulum by binding to its cytoplasmic tail
}

\author{
Armen Petrosyan ${ }^{\mathrm{a}, \mathrm{b}}$, Mohamed F. Ali ${ }^{\mathrm{a}, \mathrm{b}}$, Shailendra Kumar Verma ${ }^{\mathrm{b}}$, Helen Cheng ${ }^{\mathrm{b}}$, Pi-Wan Cheng ${ }^{\mathrm{a}, \mathrm{b}, \mathrm{c}, *}$ \\ a Omaha Western Iowa Health System, VA Service, Department of Veterans Affairs Medical Center, Omaha, NE, United States \\ ${ }^{\mathrm{b}}$ Department of Biochemistry and Molecular Biology, College of Medicine, University of Nebraska Medical Center, Omaha, NE, United States \\ ${ }^{\mathrm{c}}$ Eppley Institute for Research in Cancer and Allied Diseases, University of Nebraska Medical Center, Omaha, NE, United States
}

\section{A R T I C L E I N F O}

\section{Article history:}

Received 14 December 2011

Received in revised form 14 March 2012

Accepted 4 April 2012

Available online 13 April 2012

\section{Keywords:}

Glycosyltransferase Golgi-to-ER transport

Non-muscle myosin IIA

Heat shock proteins

Proteasome

Golgi remodeling

\begin{abstract}
A B S T R A C T
The mechanism of the Golgi-to-ER transport of Golgi glycosyltransferases is not clear. We utilize a cell line expressing the core $2 \mathrm{~N}$-acetylglucosaminyltransferase-M (C2GnT-M) tagged with c-Myc to explore this mechanism. By immunoprecipitation using anti-c-Myc antibodies coupled with proteomics analysis, we have identified several proteins including non-muscle myosin IIA (NMIIA), heat shock protein (HSP)-70 and ubiquitin activating enzyme $\mathrm{E} 1$ in the immunoprecipitate. Employing yeast-two-hybrid analysis and pulldown experiments, we show that the C-terminal region of the NMIIA heavy chain binds to the 1-6 amino acids in the cytoplasmic tail of C2GnT-M. We have found that NMIIA co-localizes with C2GnT-M at the periphery of the Golgi. In addition, inhibition or knockdown of NMIIA prevents the brefeldin A-induced collapse of the Golgi as shown by the inhibition of the migration of both Giantin, a Golgi matrix protein, and C2GnT-M, a Golgi non-matrix protein, to the ER. In contrast, knockdown of HSP70 retains Giantin in the Golgi but moves C2GnT-M to the ER, a process also blocked by inhibition or knockdown of NMIIA. Also, the intracellular distribution of C2GnT-M is not affected by knockdown of $\beta$-coatomer protein with or without inhibition of HSPs, suggesting that the Golgi-to-ER trafficking of C2GnT-M does not depend on coat protein complex-I. Further, inhibition of proteasome results in accumulation of ubiquitinated C2GnT-M, suggesting its degradation by proteasome. Therefore, NMIIA and not coat protein complex-I is responsible for transporting the Golgi glycosyltransferase to the ER for proteasomal degradation. The data suggest that NMIIA is involved in the Golgi remodeling.
\end{abstract}

(c) 2012 Elsevier Ltd. All rights reserved.

\section{Introduction}

Golgi structure-function relationships have been debated among cell biologists since the discovery of the Golgi in 1898 (Marsh and Howell, 2002; Nakamura, 2010), indicating that there is still a lot we do not know about this organelle. Golgi apparatus is a posttranslational modification and sorting station of the cargos in mammalian secretory pathway. It is a dynamic organelle constantly undergoing remodeling, and made of two groups of resident proteins, matrix and non-matrix (Munro, 2011; Puri et al., 2004). The Golgi matrix proteins, which include proteins such as GM130, Giantin, etc., form the Golgi scaffold and can serve as the

Abbreviations: $\quad \mathrm{C} 2 \mathrm{GnT}-\mathrm{M} / 2$, Core $2 \beta 1,6 \mathrm{~N}$-acetylglucosaminyltransferase mucus-type or isozyme 2; NMIIA, non-muscle myosin IIA; HSP, heat shock protein; COP, coat protein complex.

* Corresponding author at: Department of Biochemistry and Molecular Biology, University of Nebraska Medical Center, 985870 Nebraska Medical Center, Omaha, NE 68198-5870, United States. Tel.: +1 402559 5776; fax: +1 4025596650.

E-mail address: pcheng@unmc.edu (P.-W. Cheng). docking sites for transport vesicles (Appenzeller-Herzog and Hauri, 2006). The Golgi non-matrix proteins, which include enzymes such as glycosyltransferases, carry out posttranslational modification of the cargos as they pass through the Golgi. The Golgi glycosyltransferases are type II membrane proteins synthesized in the ER where they acquire proper conformation with the help of chaperones such as heat shock proteins (Walter and Buchner, 2002). Then, they are transported to various compartments of the Golgi largely according to the steps they participate in the assembly of conjugated glycans. The Golgi localization signals of glycosyltransferases reside in the $\mathrm{N}$-terminal region, which includes a cytoplasmic tail, a transmembrane domain, and a stem (Aoki et al., 1992; Burke et al., 1994; Colley, 1997; El-Battari, 2006; Nilsson et al., 1996). The cytoplasmic tail contributes to the retention of a glycosyltransferase to the Golgi by binding to a protein in a glycosyltransferase-specific manner (Osman et al., 1996; Quintero et al., 2008; Wassler et al., 2001; Schmitz et al., 2008). To date, only four mammalian glycosyltransferases of which binding proteins have been identified (Grabenhorst and Conradt, 1999; Schaub et al., 2006; Tu et al., 2008; Tu and Banfield, 2010; Uliana et al., 2006). The ER-to-Golgi transport of the Golgi proteins is also determined by the cytoplasmic tail 
(Giraudo and Maccioni, 2003; Guo and Linstedt, 2006; Watanabe and Riezman, 2004). Coat protein complex (COP) II is known to be involved in the ER-to-Golgi anterograde transport of Golgi proteins (King, 2000; Palmer et al., 2009; Presley et al., 1997; Storrie et al., 1998). But, whether this applies to Golgi glycosyltransferases is not known. Although the cytoplasmic tails of the Golgi enzymes have been shown to be essential for their Golgi-to-ER transport (Okamoto et al., 2008; Uemura et al., 2009), the exact role played by the cytoplasmic tails remains to be established.

Non-muscle myosin IIA (NMIIA) is a member of the actin-based molecular motors (Bray, 2001; Fath, 2005; Ludowyke et al., 2006; Richards and Cavalier-Smith, 2005), which is composed of two heavy chains and two pairs of light chains. The C-terminal region of NMIIA heavy chains contains the cargo-binding site while the $\mathrm{N}$-terminal region contains ATPase and actin-binding sites, which enable NMIIA to walk on actin filaments to transport the cargos (Conti and Adelstein, 2008; Sellers, 2000). NMIIA is known to be involved in the Golgi-to-ER transport of Golgi proteins (Duran et al., 2003; Vazhappilly et al., 2010). However, its role in the Golgi-to-ER transport of glycosyltransferases is not known.

In this communication, we show that core $2 \mathrm{~N}$ acetylglucosaminyltransferase-M/2 (C2GnT-M), the enzyme that synthesizes all three $\beta 6$ GlcNAc branch structures found in secreted mucins (Cheng and Radhakrishnan, 2011; Ropp et al., 1991; Schwientek et al., 1999; Yeh et al., 1999), utilizes a COPIindependent mechanism for its Golgi-to-ER transport. We show that NMIIA is responsible for transporting C2GnT-M to the ER by binding to the cytoplasmic tail of this enzyme. After transported to the ER, the enzyme is degraded by proteasome. We conclude that NMIIA is involved in transporting this Golgi enzyme to the ER for recycling.

\section{Methods}

\subsection{Materials}

The reagents were obtained from the following suppliers: C-Myc (mouse monoclonal and rabbit polyclonal) and $\gamma$-tubulin (mouse monoclonal) Abs, Santa Cruz Biotechnology (Santa Cruz, CA); rabbit polyclonal Abs against the peptide GKADGAEAKPAE located at the C-terminus of the NMIIA heavy chain, mouse monoclonal anti- $\beta$-actin Ab, trypsin (Type IX), and NMIIA inhibitor Blebbistatin, Sigma (St. Louis, MO); anti-human C2GnT-M goat polyclonal Abs, Everest Biotech (Oxfordshire, UK); rabbit polyclonal Abs (antiGiantin, anti-protein disulfide isomerase (PDI), and anti-ubiquitin), and mouse anti- $\beta$-COP and anti-HSP70 Abs, Abcam (Cambridge, MA); horseradish peroxidase-conjugated secondary Abs (donkey anti-rabbit, donkey anti-mouse, and donkey anti-goat), Jackson ImmunoResearch (West Grove, PA); BFA, KNK437, and proteasome inhibitor, MG-132, EMD Chemicals (Brookfield, WI).

\subsection{Cell culture and siRNA treatment}

Panc1-bC2GnT-M (c-Myc) cells were prepared and cultured as previously described (Choi et al., 2005). Blebbistatin, BFA, KNK437, and MG-132 were dissolved in DMSO, and diluted in medium immediately before use. Cells treated with a corresponding amount of DMSO were used as the control. MYH9 (myosin, heavy polypeptide 9 , non-muscle), HSPA8 (heat shock $70 \mathrm{kDa}$ protein 8 ) and scrambled on-targetplus smartpool siRNA were purchased from Dharmacon (Chicago, IL). Pool of 3 siRNAs targeting COPB was obtained from Santa Cruz Biotechnology. Panc1-bC2GnTM (c-Myc) cells were transfected with 150-300 nM siRNAs using Liofectamine RNAi MAX reagent (Invitrogen, Carlsbad, CA). After cultured for $72 \mathrm{~h}$, cells were analyzed by Western blotting.

\subsection{Co-immunoprecipitation (Co-IP) and transfection}

For identification of proteins in the complexes pulled down by Co-IP, confluent Panc1-bC2GnT-M (c-Myc) cells cultured on a T-75 flask were harvested by trypsinization, neutralized with soybean trypsin inhibitor, and then lysed with $1.5 \mathrm{ml}$ of a non-denaturing lysis buffer, which contained $50 \mathrm{mM}$ Tris (pH 7.4), $150 \mathrm{mM} \mathrm{NaCl}$, $5 \mathrm{mM}$ EDTA, $0.5 \% \mathrm{NP}-40(\mathrm{w} / \mathrm{w})$, and $1 \%(\mathrm{v} / \mathrm{v})$ of mammalian protease inhibitor cocktail (Sigma). One milliliter of cell lysate was pre-cleared with $50 \mu \mathrm{l}$ of irrelevant antibody $(1 \mathrm{mg} / \mathrm{ml})$ of same species and isotype as that to be employed for IP for $1 \mathrm{~h}$ at $4{ }^{\circ} \mathrm{C}$. It was followed by incubation with $100 \mu$ l of a $50 \%$ slurry of protein $\mathrm{G}$ plus agarose (EMD) at $4{ }^{\circ} \mathrm{C}$ for $1 \mathrm{~h}$ with gentle rocking. An aliquot of the supernatant was incubated with anti-c-Myc C2GnT-M or NMIIA Abs $(1.5 \mu \mathrm{g}$ Abs to $400 \mu \mathrm{g}$ protein in $1 \mathrm{ml}$ cell lysate) overnight at $4{ }^{\circ} \mathrm{C}$ with gentle rocking. Then, $50 \mu \mathrm{l}$ of protein $\mathrm{G}$ agarose slurry was added and incubated for $1 \mathrm{~h}$ at $4{ }^{\circ} \mathrm{C}$ to capture the immunocomplexes, which were then analyzed by SDSPAGE.

\subsection{Gel electrophoresis and immunoblotting}

Proteins were separated on SDS-PAGE on mini-gels and electrotransferred to PVDF membranes. After blocking in PBS solution containing $5 \%$ nonfat dried milk and $0.1 \%$ Tween-20 (PBST) at RT for $1 \mathrm{~h}$, the membranes were incubated at $4{ }^{\circ} \mathrm{C}$ overnight in same blocking solution containing primary Abs. Following washing with PBS (pH 7.4) containing 0.1\% Tween-20, the membranes were incubated with HRP-conjugated secondary Abs for $1 \mathrm{~h}$. Immunoreactive bands were detected by Thermo Scientific SuperSignal West Pico Chemiluminescent Substrate reagents and exposed to BioExpress Blue Basic Autorad chemiluminescence film (Kaysville, UT). The bands on the autoradiography films were scanned with Scanjet 6200C (Hewlett Packard) driven by Adobe Photoshop.

\subsection{Immunofluorescence staining and confocal fluorescence microscopy}

Panc1-bC2GnT-M (c-Myc) cells grown overnight on cover slips were fixed in $4 \%$ paraformaldehyde/PBS at RT for $30 \mathrm{~min}$. After treated with mouse anti-c-Myc and rabbit anti-NMIIA Abs $(1: 100)$ at $37^{\circ} \mathrm{C}$ for $1 \mathrm{~h}$, the cells were stained with fluorochromeconjugated DyLight 488 donkey anti-mouse Ab (green), and DyLight 594 donkey anti-rabbit Ab (red) (1:200) and mounted in ProLong Gold antifade reagent with and without DAPI (Invitrogen). After deparaffinization, human bronchial epithelial tissue sections were rinsed with water and then treated with Tris/EDTA ( $\mathrm{pH} 9$ ) buffer in a microwave for $20 \mathrm{~min}$ to retrieve the antigen. Following blocking with $1 \%$ donkey serum for $1 \mathrm{~h}$ at RT, the sections were incubated with anti-C2GnT-M goat polyclonal (1:50) and rabbit polyclonal anti-Giantin Abs $(1: 150)$ for $1 \mathrm{~h}$ at RT, followed by treatment for $1 \mathrm{~h}$ at RT with fluorochrome-conjugated DyLight 488 donkey anti-goat Ab (green), and DyLight 594 donkey anti-rabbit secondary Ab (red) (1:200). The treated tissue sections were mounted in ProLong Gold antifade reagent containing DAPI. Stained cells and tissue sections were viewed under a Zeiss 510 meta confocal laser scanning microscope. Images were analyzed using Zeiss 510 software. For some figures, image analysis was performed using the Adobe Photoshop and the ImageJ.

\subsection{Proteomics analysis of electrophoretically separated proteins}

The SDS-PAGE separated and Coomassie blue-stained bands were excised, trypsinized, and treated with $60 \%$ acetonitrile 
containing $0.1 \%$ trifluoroacetic acid to extract the peptides. The peptides were analyzed by the Thermo Fisher LCQ Deca Plus system liquid chromatograph ion trap mass spectrometry with peaks subjected to MS/MS fragmentation by collision-induced dissociation. Full mass spectra of parent ions and MS/MS fragmentation data were processed using BioWorks 3.2 software based on SEAQUEST algorithm. Proteomics analysis of these protein bands was carried out by the mass spectrometry and proteomics core facility at UNMC.

\subsection{Cloning, expression and purification of the C-terminal region of human non-muscle myosin heavy chain 9 (MYH9) in E. coli}

The RNA of A549 cells was used for PCR cloning of the cDNA of the C-terminal 1682-1960 aa of NMIIA heavy chain 9 (MYH9, accession no. NM_002473.3). The forward primer "MYH9-For" 5'-TAGGATCCATGATCCAGTTGCAGGAGGAACTG-3' and the reverse primer "MYH9-Rev" 5'ATGAATTCATTTTCGGCAGGTTTGGCCTCAGC-3' were used. The restriction sites BamHI and EcoRI are underlined. The purified PCR product $(840 \mathrm{bp})$ was cloned into the $3^{\prime}$ end of the GST fusion protein flanked by a Precision protease cleavage site $(-)$ located in LeuGlcValLeuPheGlnGly-Pro sequence in the pGEX$6 \mathrm{P}-2$ vector (GE health care, Piscataway, NJ). This plasmid DNA was amplified in high efficiency competent DH5 Escherichia coli (New England Biolab, Ipswich, MA) and then used to transform the BL21 (DE3) E. coli. A single clone was cultured in $100 \mathrm{ml} \mathrm{LB}$ medium containing ampicillin $(100 \mu \mathrm{g} / \mathrm{ml})$. The $E$. coli culture at the logarithmic phase (OD600 0.6) was induced with $0.5 \mathrm{mM}$ isopropylthiogalactoside (IPTG) at $37^{\circ} \mathrm{C}$ for $3 \mathrm{~h}$. The cell pellet was dissolved in $10 \mathrm{ml}$ lysis buffer $(10 \mathrm{ml}$ PBS; $80 \mu \mathrm{l} 100 \mathrm{mM}$ PMSF; $10 \mu \mathrm{l} 1 \mathrm{M}$ DTT; $80 \mu \mathrm{l} \mathrm{NP-40}$ and a tablet of Roche protease inhibitor cocktail mini (Indianapolis, IN) and lysed 3 times with French press (Thermo Scientific). The supernatant $(13,000 \times g$, $40 \mathrm{~min}$ at $4{ }^{\circ} \mathrm{C}$ ) was mixed with $1 \mathrm{ml}$ of glutathione resin (Genscript, Piscataway, NJ) to immobilize the recombinant protein. The beads were suspended in $1.5 \mathrm{ml}$ of PBS containing $40 \mu \mathrm{g}$ of GST-tagged Precision protease (GE health care) to cleave the recombinant protein from the resin. After rocked at $4{ }^{\circ} \mathrm{C}$ for $16 \mathrm{~h}$, the supernatant was mixed with $500 \mu$ l of fresh glutathione resin to remove the Precision GST-protease. The purity of the $32 \mathrm{kDa}$ recombinant MYH9 protein in the supernatant was assessed with $10 \%$ SDS-PAGE.

\subsection{Isolation of NMIIA in Panc1-bC2GnT-M (c-Myc) cell lysates or recombinant MYH9 with biotinylated $N$-terminal 21 and 7 amino acid (aa) peptides of hC2GnT-M}

A 21 aa peptide, which includes the cytoplasmic tail (MVQWKRLCQLHYL) and a portion of the transmembrane domain (WALGCYM) located at the N-terminus of hC2GnT-M, was tagged with a biotin at the C-terminus (LifeTein LLC, South Plainfield, NJ). A 15 aa peptide (LCQLHYLWALGCYMK) tagged with biotin at the C-terminus served as the control. An N-terminal 7 aa peptide (MVQWKRL) was tagged with biotin at the Met (AAPPTec LLC, Louisville, KY). To isolate NMIIA, $20 \mu \mathrm{l}$ of hC2GnT-M peptide in $25 \%$ acetic acid $(0.1 \mathrm{mg} / \mathrm{ml})$ was mixed with $20-40 \mu$ l of cell lysate $(1.5-3.5 \mathrm{mg} / \mathrm{ml}$ of protein) containing $5 \% \beta$-mercaptoethanol or $100 \mu \mathrm{l}$ of purified C-terminal part of NMIIA heavy chain 9 (MYH9) $(0.5 \mathrm{mg} / \mathrm{ml})$. After incubation at $37^{\circ} \mathrm{C}$ for $1 \mathrm{~h}, 100 \mu \mathrm{l}$ of Dynabeads M-280 streptavidin (Dynal, Norway) was added. Following gentle rotation for additional $30 \mathrm{~min}$, the beads with immobilized complexes were trapped with a magnet. The captured proteins were separated on $8 \%$ SDS-PAGE followed by Western blotting with rabbit anti-NMIIA Abs.

\subsection{Trypsin digestion of the biotinylated peptide to remove the $\mathrm{N}$-terminal 6 aa's}

To identify the region of the biotinylated hC2GnT-M 21 aa peptide, which binds to NMIIA, this peptide was digested with trypsin at RT in a $5 \mathrm{mM}$ potassium-phosphate buffer, $\mathrm{pH} 7.0$ for $30 \mathrm{~min}$ with an enzyme-to-substrate ratio of 1:500 by weight. After addition of soybean trypsin inhibitor, the biotinylated peptide was isolated by Dynabeads and then exposed to the cell lysate or MYH9 solution to assess the ability of the biotinylated peptide to pull down NMIIA in the cell lysate or purified MYH9 peptide.

\subsection{Yeast-two-hybrid analysis of the interactions between the 1507-1960 a peptide of the NMIIA heavy chain and the cytoplasmic peptide of hC2GnT-M}

The plasmids encoding GAL4(DBD)-C2GnT-M (1-10aa) or GAL4(DBD)-C2GnT-M (1-10 aa, AAA ${ }^{6}$ were co-transformed with GAL4(AD)-NMIIA (444 aa peptide, 1507-1960, of NMIIA heavy chain) into yeast Y2HGold (Clontech). In the other series of experiments the plasmids encoding GAL4(DBD)-C2GnT$\mathrm{M}^{(1-14)} \quad\left(\mathrm{M}^{1} \mathrm{VQWKRLCQLHYLW}^{14}\right), \quad$ GAL4(DBD)-C2GnT-M ${ }^{(\Delta 2,3)}$, GAL4(DBD)-C2GnT-M( $(\Delta 4-6), \quad$ GAL4(DBD)-C2GnT-M $(\Delta 7-9)$, GAL4(DBD)-C2GnT-M(1010) or GAL4(DBD)-C2GnT-M( ${ }^{(\Delta 13,14)}$ were co-transformed with GAL4(AD)-NMIIA into yeast Y2HGold. Interaction of GAL4(DBD) and GAL4(AD) fusion proteins enables the cells to grow in the absence of His and in the presence of Aureobasidin A antibiotic. Cotransformants which survive Leu( $(-)$ and $\operatorname{Try}(-)$ conditions were spotted at $1.5 \times 10^{7}$ cells $/ 10 \mu \mathrm{l}$ concentration onto plates lacking His and containing $100 \mathrm{ng} / \mathrm{ml}$ Aureobasidin A. The plates were incubated at $30^{\circ} \mathrm{C}$ for $5-7 \mathrm{~d}$ before being photographed. The Gal4(DBD)-p53 and Gal4(AD)-SV40 large $\mathrm{T}$ antigen (Ali and DeCaprio, 2001) pair was used as a positive control while Gal4(DBD)-Lamin and Gal4(AD)-SV40 large T antigen pair was used as a negative control.

\subsection{Miscellaneous}

Protein concentrations were determined with the Coomassie Plus Protein Assay (Pierce Chemical Co., Rockford, IL) using BSA as the standard. Data are expressed as mean \pm SEM. Analysis was performed using 2 -sided $t$-test. A value of $P<0.05$ was considered statistically significant.

\section{Results}

\section{1. bC2GnT-M forms complexes with NMIIA in Panc1-bC2GnT-M (c-Myc) cells}

Current study was initiated based on a preliminary observation that multiple c-Myc-carrying protein bands with sizes greater than that $(55 \mathrm{kDa})$ of bC2GnT-M were detected in the Panc1-bC2GnT$\mathrm{M}$ (c-Myc) cell lysates (data not shown). The results suggested that bC2GnT-M formed complexes with other cellular proteins. To identify these proteins, the complexes were isolated from the cell lysate using anti-c-Myc Abs plus protein G Agarose. The proteins in the complexes were separated on SDS-PAGE under non-reducing conditions and then stained with Coomassie blue (Fig. 1A). Proteomic analysis of the 4 high molecular weight bands showed: band 1 contained the heavy chains of NMIIA and NMIIB, band 2 contained cytoskeletal keratin, type II and also heavy chains of NMIIA and IIB, band 3 contained cytoskeletal keratin, type II, and band 4 contained gelsolin isoform. Subsequent proteomics analysis of same samples run under reducing conditions identified additional proteins on Coomassie blue-stained bands. They include ubiquitin activating enzyme E1, HSP90 1 $\beta$, and five different HSP70s (Fig. S1). Because 


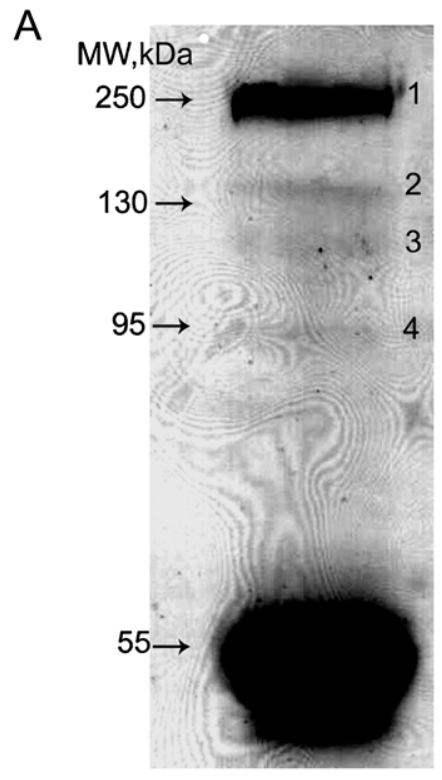

B 1 maqqaadkyl yvdknfinnp laqadwaakk lvwvpsdksg fepaslkeev geeaivelve 61 ngkkvkvnkd diqkmnppkf skvedmaelt clneasvlhn lkeryysgli ytysglfcvv 121 inpyknlpiy seeivemykg kkrhempphi yaitdtayrs mmqdredqsi lctgesgagk 181 tentkkviqy layvasshks kkdqgelerq llqanpilea fgnaktvknd nssrfgkf ir 241 infdvngyiv ganietylle ksrairqake ertfhifyyl lsgagehlkt dlllepynky 301 rflsnghvti pgqqdkdmfq etmeamrimg ipeeeqmgll rvisgvlqlg nivfkkernt 361 dqasmpdnta aqkvshllgi nvtdftrgil tprikvgrdy vqkaqtkeqa dfaiealaka 421 tyermfrwlv lrinkaldkt krqgasfigi ldiagfeifd lnsfeqlcin ytneklqqlf 481 nhtmfilege eygregiewn fidfgldlop cidliekpag ppgilallde ecwfpkatdk 541 sfvekrmgeq gthpkfqkk 601 s. 601 hqssdkr 721 renple 721 yeiltpnsip kgfndgkqac vlmikaleld snlyrigqsk vefragvlah leeerdikit 781 dviigfqacc rgylarkafa krqqq1tamk vlqrncaayl klrnwqwwrl ftkvkpllqv 841 srqeeemmak eeelvkvrek qlaaenrlte metlqsqlma eklqlqeqlq aetelcaeae 901 elrarltakk qeleeichdl earveeeer cqhlqaekkk mqqniqelee qleeesarq 961 klqlekvtte aklkkleeeq iiledqnckl akekklledr iaefttnlte eeekskslak 1021 lknkheamit dleerlrree kqrqelektr rklegdstdl sdqiaelqaq iaelkmqlak 1081 keeelqaala rveeeaaqkn malkkirele sqiselqedl eserasrnka ekqkrdlgee 1141 lealkteled tldstaaqqe 1 rskreqevn ilkktleeea ktheaqigem rqkhsqavee 1201 laeqleqtkr vkanlekakq tlenergela nevkvllqgk gdsehkrkkv eaqlqelqvk 1261 fnegervrte ladkvtklqv eldnvtglls qsdskssklt kdfsalesql gdtgellgee 1321 nrqklslstk lkqvedekns freqleeee akhnlekqia thaquadmk kkmedsvgcl 1381 etaeevkrkl qkdleglsqr heekvaaydk lektktrlqq elddllvdld hqrqsacnle 1441 kkqkkfdql l aeektisaky aeerdraeae areketkals laraleeame gkaelerlnk 1501 gfrt 1561 qremedim sskdagks helekskral eqqueemktq leeledelqa tedaklrlev 1561 miqak 1621 dleahidsan knrdealkql rklqaqmkdc mrelddtras reellaqake nekklksmea 1681 emiqlqeela aaerakrqaq qerdeladei anssgkgala leekrrlear laqleeelee 1741 eqgntelind rlkkanlqid qintdlnler shaqknenar qqlerqnkel kvklqemegt 1801 vkskykasit aleakiaqle eqlanetker qaackqvrrt ekklkdvllq vdderrnaeg 1861 ykdqadkast rlkqlkrqle eaeeeagran asrrklqrel edatetadam nrevsslknk 1921 lrrgdlpfvv prrmarkgag dgsdeevdgk adgaeakpae

C

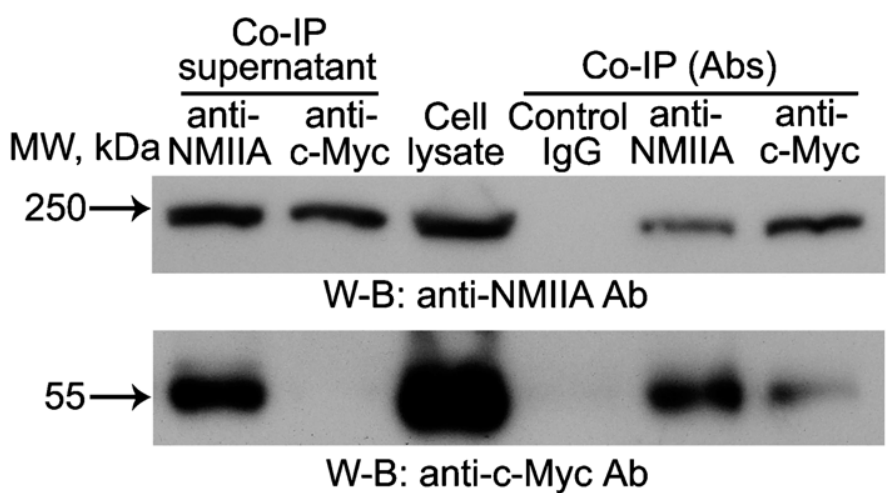

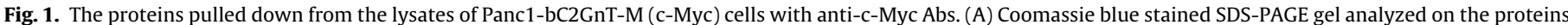

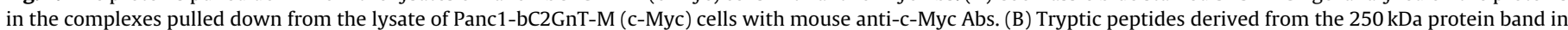

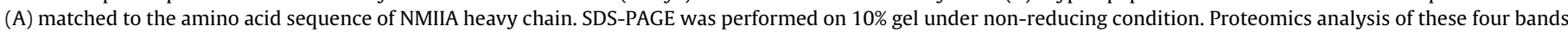

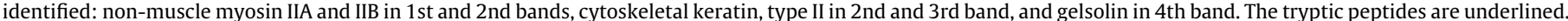

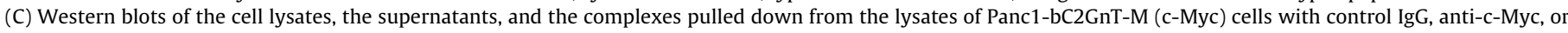

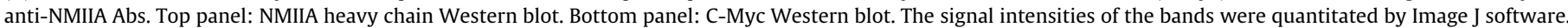

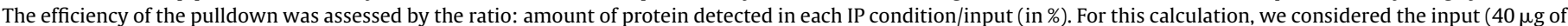

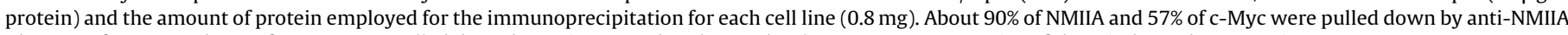
Abs, 76\% of NMIIA and 97\% of c-Myc were pulled down by anti-c-Myc Abs. The results shown are representative of three independent experiments.

21 tryptic peptides derived from band 1 matched the amino acid sequence of the heavy chain of NMIIA (Fig. 1B), we chose to characterize NMIIA as a possible bC2GnT-M binding partner further.

Supplementary material related to this article found, in the online version, at http://dx.doi.org/10.1016/j.biocel.2012.04.004.

We found that NMIIA was pulled down by anti-c-Myc Abs, and bC2GnT-M by anti-NMIIA Abs (Fig. 1C). The results confirmed that bC2GnT-M formed complexes with NMIIA. It was noted that about $57 \%$ of C2GnT-M was pulled down by anti-NMIIA Abs while about $76 \%$ of NMIIA was pulled down with anti-c-Myc Abs.

\subsection{C2GnT-M interacts with the C-terminal region of NMIIA heavy chain via the cytoplasmic tail}

Because the cytoplasmic tails of several Golgi glycosyltransferases were shown to form complexes with cytoplasmic proteins (Giraudo and Maccioni, 2003; Guo and Linstedt, 2006; Tu et al., 2008), we proceeded to determine if the cytoplasmic tail of C2GnT$\mathrm{M}$ could pull down NMIIA. As shown in Fig. 2A, a C-terminally biotinylated $1-21$ aa peptide of hC2GnT-M, which contained the cytoplasmic tail (1-7 aa, MVQWKRL), pulled down NMIIA (lane 1). Following removal of the 6 amino acids (1-6aa) with trypsin, the 7-21 aa peptide no longer could pull down NMIIA (lane 3 ). The results were confirmed by the pulldown of NMIIA using a biotinylated $1-7$ aa peptide that contains the 6 aa's removed by trypsin (lane 2).

To identify the region of NMIIA heavy chain involved in its interaction with C2GnT-M, we performed a pull-down of the recombinant C-terminal region (1682-1960 aa) of the NMIIA heavy chain with the biotinylated 1-21 aa peptide of hC2GnT-M. As shown in Fig. 2B, the recombinant protein was pulled down by the 1-21 aa peptide of hC2GnT-M (lane 2) but not the 7-21 aa peptide (lane 1). These data indicate that the C-terminal portion of NMIIA heavy chain contains the sequence responsible for NMIIA binding to the C2GnT-M cytoplasmic tail.

The interaction of the cytoplasmic tail of hC2GnT-M with NMIIA was confirmed by yeast-two-hybrid analysis using a 454 aa peptide at the C-terminal region (1507-1960 aa) of the NMIIA heavy chain as the prey and 1-10 aa peptide of hC2GnT-M as the bait. The wild-type 1-10 aa peptide of hC2GnT-M showed a moderate 

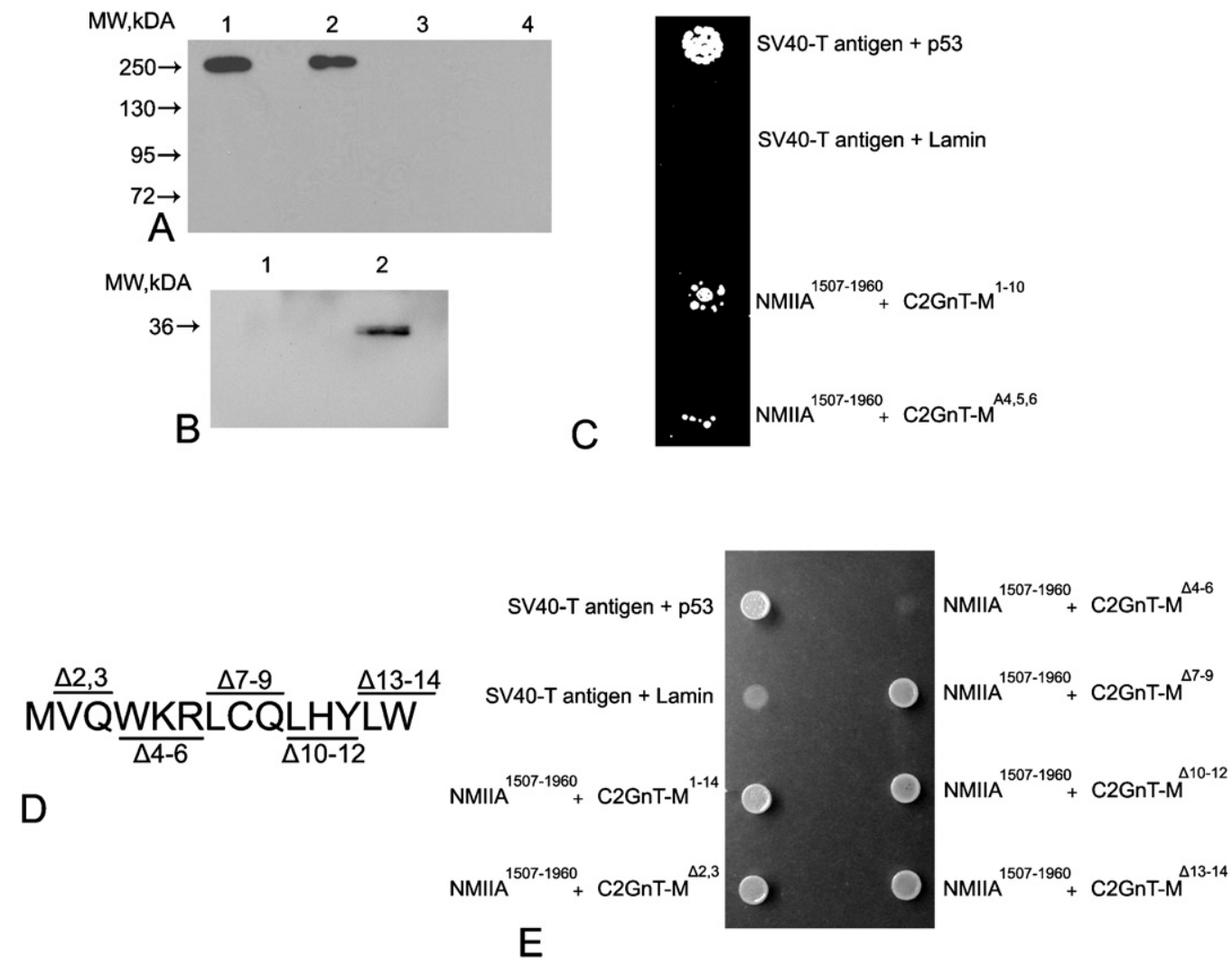

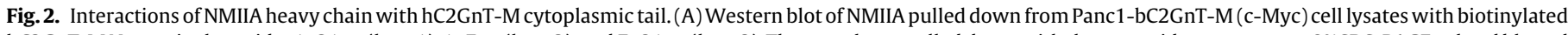

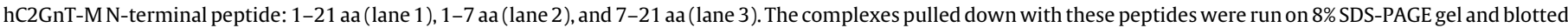

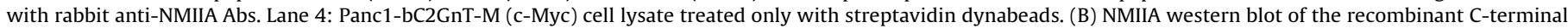

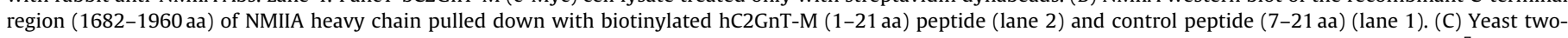

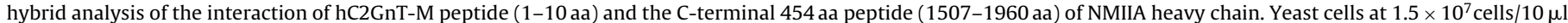

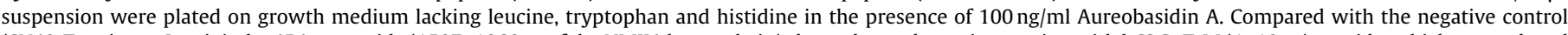

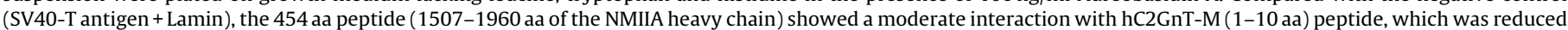

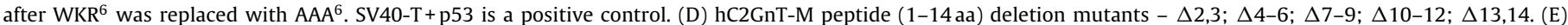

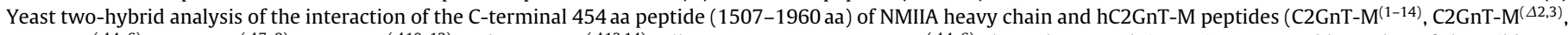

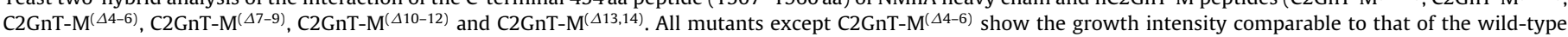
peptide in the absence of histidine and presence of Aureobasidin A.

interaction with the 454 aa peptide of the NMIIA heavy chain. The interaction was substantially reduced when $\mathrm{WKR}^{6}$ was replaced with $\mathrm{AAA}^{6}$, suggesting that these three amino acids play a critical role in the binding of C2GnT-M with NMIIA (Fig. 2C). Further experiment employing a series of deletion mutants has confirmed the importance of WKR for the binding of C2GnT-M with NMIIA. As shown in Fig. 2D and E, interaction of C2GnT-M cytoplasmic tail with NMIIA was substantially reduced after WKR ${ }^{6}$ deletion (C2GnT-

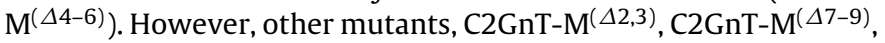

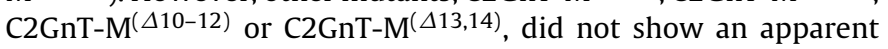
reduction in their interaction with NMIIA heavy chain when compared with wild-type peptide.

\subsection{Intracellular distribution of bC2GnT-M and NMIIA in Panc1-bC2GnT-M cells}

To confirm that NMIIA formed complexes with bC2GnT$\mathrm{M}$ in the cells, confocal immunofluorescence microscopy was employed. C2GnT-M was found to co-localize with Giantin, a Golgi matrix protein (Fig. 3A-C). Also, C2GnT-M co-localized with NMIIA at the cytoplasmic boundary of the Golgi stacks (Fig. 3D-G, arrows indicate peri-Golgi staining of NMIIA). Treatment with a NMIIA inhibitor Blebbistatin $(100 \mu \mathrm{M}, 1 \mathrm{~h})$ (Chan et al., 2005; De Pina et al., 2007; Kovács et al., 2004; Straight et al., 2003) abolished co-localization of NMIIA with bC2GnT-M in the Golgi;
bC2GnT-M was retained in the Golgi while NMIIA was localized to the cytoplasm (Fig. 3H-K). The results indicate that bC2GnT-M and NMIIA no longer formed complexes in the Blebbistatin-treated cells, and another protein was predicted to be responsible for the Golgi retention of C2GnT-M. That result was confirmed by the failure of anti-c-Myc Abs to pull down NMIIA from the lysates of Panc1-bC2GnT-M cells treated with Blebbistatin (Fig. 3L).

We found that the Golgi localization of the recombinant C2GnTM produced in Panc1-bC2GnT-M (c-Myc) cells was the same as that found in the goblet cells of human bronchial epithelium, which produces endogenous C2GnT-M (Fig. S2). The result indicates that the Panc1-bC2GnT-M (c-Myc) cell is a suitable model for studying the Golgi-ER trafficking of C2GnT-M.

Supplementary material related to this article found, in the online version, at http://dx.doi.org/10.1016/j.biocel.2012.04.004.

\subsection{Inhibition or knockdown of NMIIA prevents BFA-induced collapse of the Golgi}

The biological significance of the Golgi co-localization of NMIIA with C2GnT-M was examined by confocal immunofluorescence microscopy following inhibition or knockdown of NMIIA coupled with BFA treatment. We found that NMIIA siRNA or Blebbistatin treatment retained bC2GnT-M in the Golgi (Fig. 4B vs. A and $\mathrm{F}$ vs. $\mathrm{G})$. As predicted, BFA treatment ( $36 \mu \mathrm{M}$ for $30 \mathrm{~min}$ ) resulted in 


\section{C2GnT-M/Giantin}
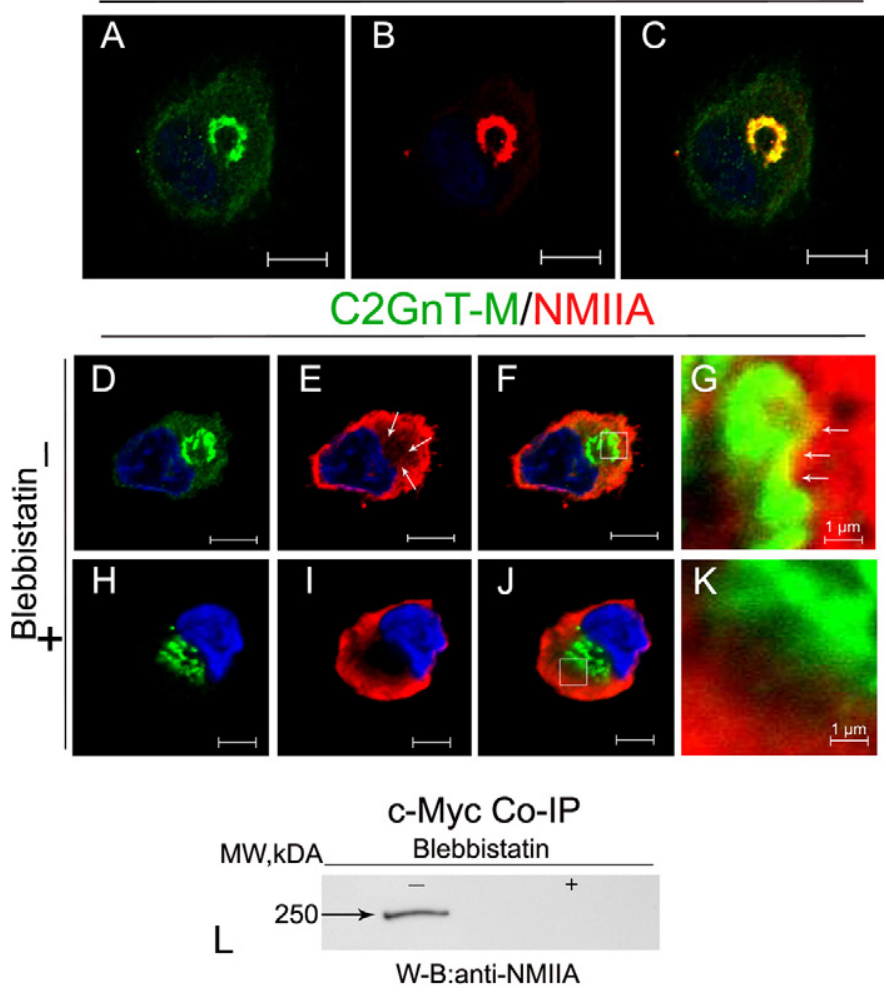

Fig. 3. Confocal immunofluorescence microscopic images of $\mathrm{C} 2 \mathrm{GnT}-\mathrm{M}$, Giantin, and NMIIA in Panc1-bC2GnT-M (c-Myc) cells. (A-C) bC2GnT-M (green) co-localizes with Giantin (red), a Golgi matrix protein; (D-G) bC2GnT-M co-localizes with NMIIA at the Golgi periphery (arrows indicate peri-Golgi staining of NMIIA). (H-K) Treatment with a NMIIA inhibitor Blebbistatin abolishes co-localization of NMIIA with bC2GnT-M in the Golgi; bC2GnT-M is retained in the Golgi while NMIIA is localized in the cytoplasm. Bars, $10 \mu \mathrm{m}$. $\mathrm{G}$ and $\mathrm{K}$ are enlarged images of $\mathrm{F}$ and $\mathrm{J}$, respectively (arrows indicate peri-Golgi co-staining of NMIIA and C2GnT-M). (L) NMIIA Western blot of the complexes pulled down with anti-c-Myc Abs from lysates of Panc1bC2GnTMc(c-Myc) cells treated with DMSO (-) or Blebbistatin (+). The amount of protein employed for the immunoprecipitation for both lane is $0.7 \mathrm{mg}$. (For interpretation of the references to color in this figure legend, the reader is referred to the web version of the article.)

the migration of C2GnT-M and Giantin from the Golgi to the ER (Fig. 4C, G, J and L vs. A, E, I and K, respectively). However, treatment with Blebbistatin or NMIIA siRNA followed by BFA resulted in the retention of C2GnT-M and Giantin in the Golgi (Fig. 4D and $\mathrm{H})$. Quantitative measurement of the distribution of C2GnT-M in the cytoplasm relative to that in the Golgi for Fig. 4A-D and E-H is shown in Fig. 4M and N, respectively. The data indicate that NMIIA is involved in the Golgi-to-ER retrograde transport of Golgi proteins because inhibition or knockdown of NMIIA prevents bC2GnT-M as well as Giantin from moving out of the Golgi even in the presence of BFA.

\subsection{Inhibition or knockdown of NMIIA inhibits the exit of C2GnT-M from the Golgi induced by inhibition of HSPs or knockdown of HSP70}

BFA is thought to cause the collapse of the Golgi by suppressing the ER-to-Golgi anterograde transport and accelerating the Golgi-to-ER transport of Golgi proteins (Burgess et al., 1991; Donaldson et al., 1990; Helms and Rothman, 1992; Ivessa et al., 1995; Lippincott-Schwartz, 1993; Puri and Linstedt, 2003). The multiple effects of BFA make this agent an undesirable Golgi disruptive compound for studying Golgi remodeling. Therefore, another agent with a simpler effect on Golgi structure is sought for studying this phenomenon.

Because several members of HSP70 were pulled down from the lysates of Panc1-bC2GnT-M cells with anti-c-Myc Abs (Fig. S1) and HSPs are chaperones known to facilitate folding of proteins in the ER and their Golgi targeting (Velez-Granell et al., 1994), we proceeded to examine the possible involvement of HSPs in the Golgi targeting of C2GnT-M. We found that HSP70 co-localized with C2GnT-M in the ER (Fig. S3) and inhibition of HSPs with KNK437 (50 $\mu \mathrm{M}, 1 \mathrm{~h})$ (Leu et al., 2009) resulted in the retention of C2GnT-M in the ER and Giantin in the Golgi (Fig. 5B and E vs. A and D, respectively; Fig. 50 vs. N). However, C2GnT-M was retained in the Golgi after the cells were treated with Blebbistatin before KNK437 (Fig. 5C, F and G). Similarly, cells treated with $150 \mathrm{nM}$ HSP70 siRNAs showed the retention of C2GnT-M in the ER (Fig. 5J vs. H; and L). However, NMIIA knockdown followed by KNK437 treatment retained C2GnT$\mathrm{M}$ in the Golgi (Fig. 5K vs. I; and L). The data are consistent with the involvement of NMIIA in the Golgi-to-ER retrograde transport of C2GnT-M. Interestingly, KNK437 treatment or HSP70 knockdown did not affect the Golgi architecture as shown by Giantin staining (Fig. 5E, I and J). This observation was different from the BFAinduced collapse of the Golgi which was shown by the migration of both C2GnT-M and Giantin from the Golgi to the ER (Fig. 4G and $\mathrm{J}$ ). Formation of complexes between C2GnT-M and HSP70 was confirmed by the pulldown of HSP70 from the cell lysate by anti-c-Myc Abs (Fig. 5P).

Supplementary material related to this article found, in the online version, at http://dx.doi.org/10.1016/j.biocel.2012.04.004.

\section{6. $\beta$-COP is not involved in the Golgi-to-ER transport of C2GnT-M}

A recent report claiming the involvement of COPI in the Golgito-ER transport of peptidyl GalNAc transferases (Gill et al., 2010) prompted us to examine whether similar transport mechanism was also employed by C2GnT-M. We found that knockdown of $\beta$-COP (Fig. 6F), a COPI component (Waters et al., 1991; Lee and Goldberg, 2010), did not affect intracellular distribution of C2GnT-M (Fig. 6C vs. A; and E). Also, $\beta$-COP knockdown did not affect the KNK437induced distribution of C2GnT-M to the ER (Fig. 6D vs. B; and E). Next, we examined $\beta$-COP distribution after inhibition of HSPs. In the control, $\beta$-COP evenly distributes throughout the cell, but after KNK437 treatment it is primarily located to the immediate vicinity of the Golgi (Fig. $6 \mathrm{H}$ vs. G). Under same conditions, C2GnT-M was found outside of the Golgi (Fig. 6J vs. I). In addition, NMIIA inhibition or knockdown did not alter $\beta$-COP distribution (Fig. S4). Collectively, the data suggest that COPI is not involved in the Golgi-to-ER transport of C2GnT-M.

Supplementary material related to this article found, in the online version, at http://dx.doi.org/10.1016/j.biocel.2012.04.004.

\subsection{C2GnT-M degradation by proteasome}

The identification of ubiquitin activating enzyme E1 in the complexes pulled down from the lysates of Panc1-bC2GnT-M (c-Myc) cells with anti-c-Myc Abs (Fig. S1) prompted us to examine if proteasome was involved in the degradation of C2GnT-M. We found that treatment of Panc1-bC2GnT-M cells with MG-132 (5 $\mu \mathrm{M}, 24 \mathrm{~h}$ ) resulted in an increase of not only total but also ubiquitinated C2GnT-M (Fig. 7A-C). The bulk of the cytoplasm was occupied by C2GnT-M in cells treated with MG-132 (Fig. 7E vs. D). In addition, Blebbistatin treatment resulted in an increase of NMIIA (Fig. 7F and $\mathrm{G})$, but a decrease in ubiquitinated bC2GnT-M (Fig. 7H). The results suggest that upon inhibition of NMIIA, the Golgi-to-ER retrograde transport of bC2GnT-M is blocked, which leads to reduction of the amount of bC2GnT-M delivered by NMIIA to the ER for degradation 

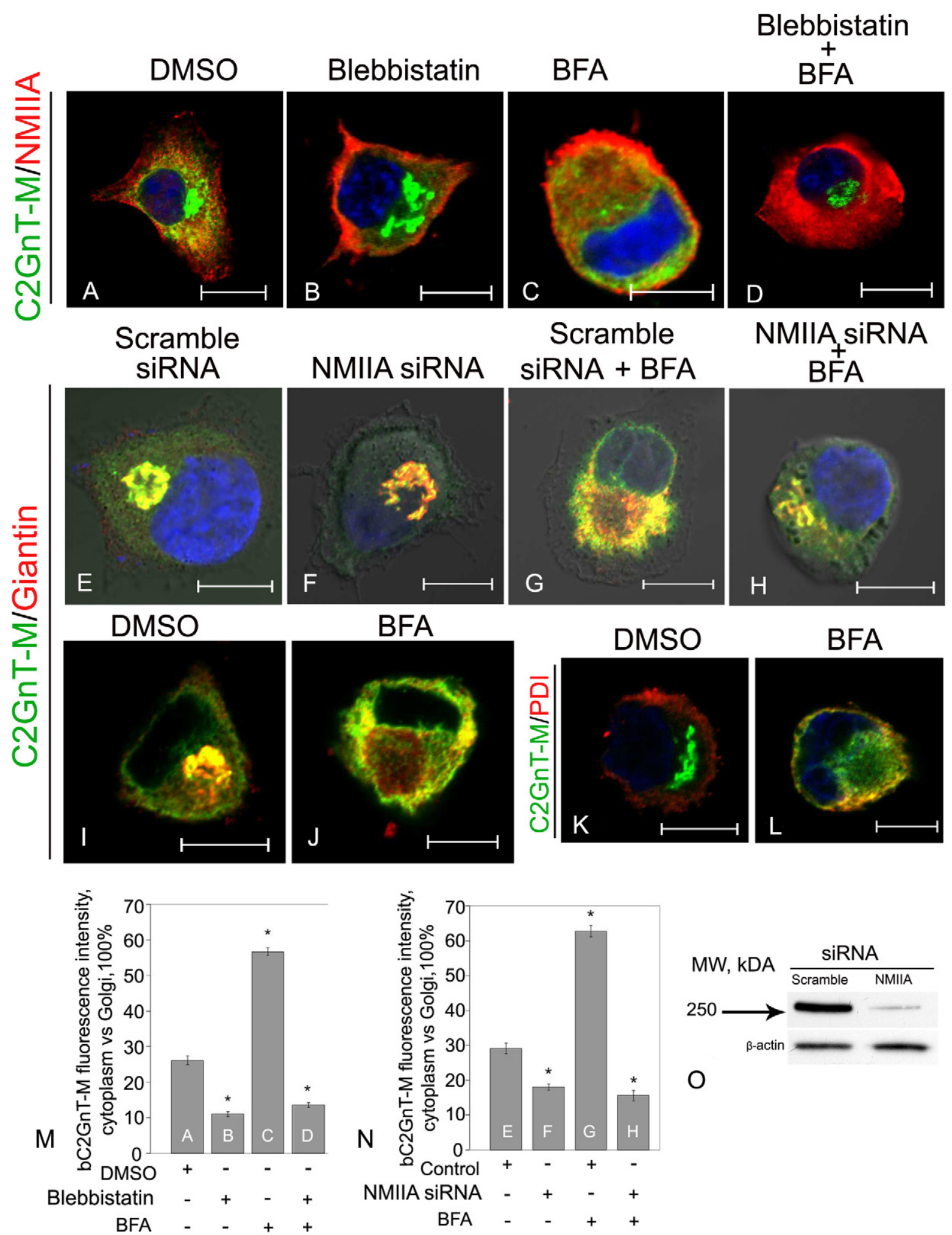

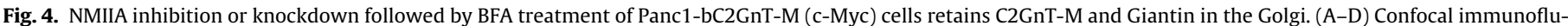

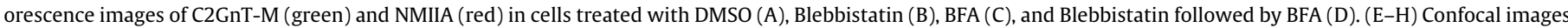

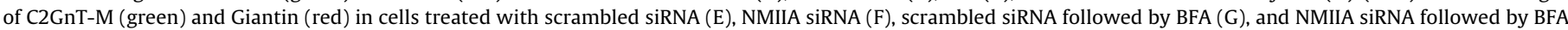

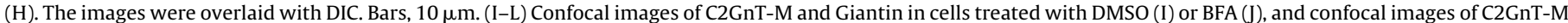

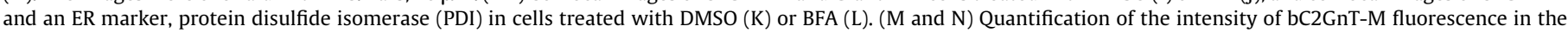

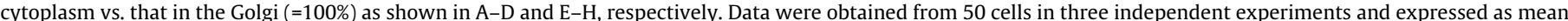

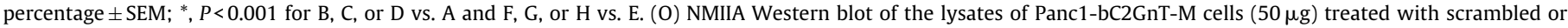
NMIIA-specific siRNAs. (For interpretation of the references to color in this figure legend, the reader is referred to the web version of the article.) 


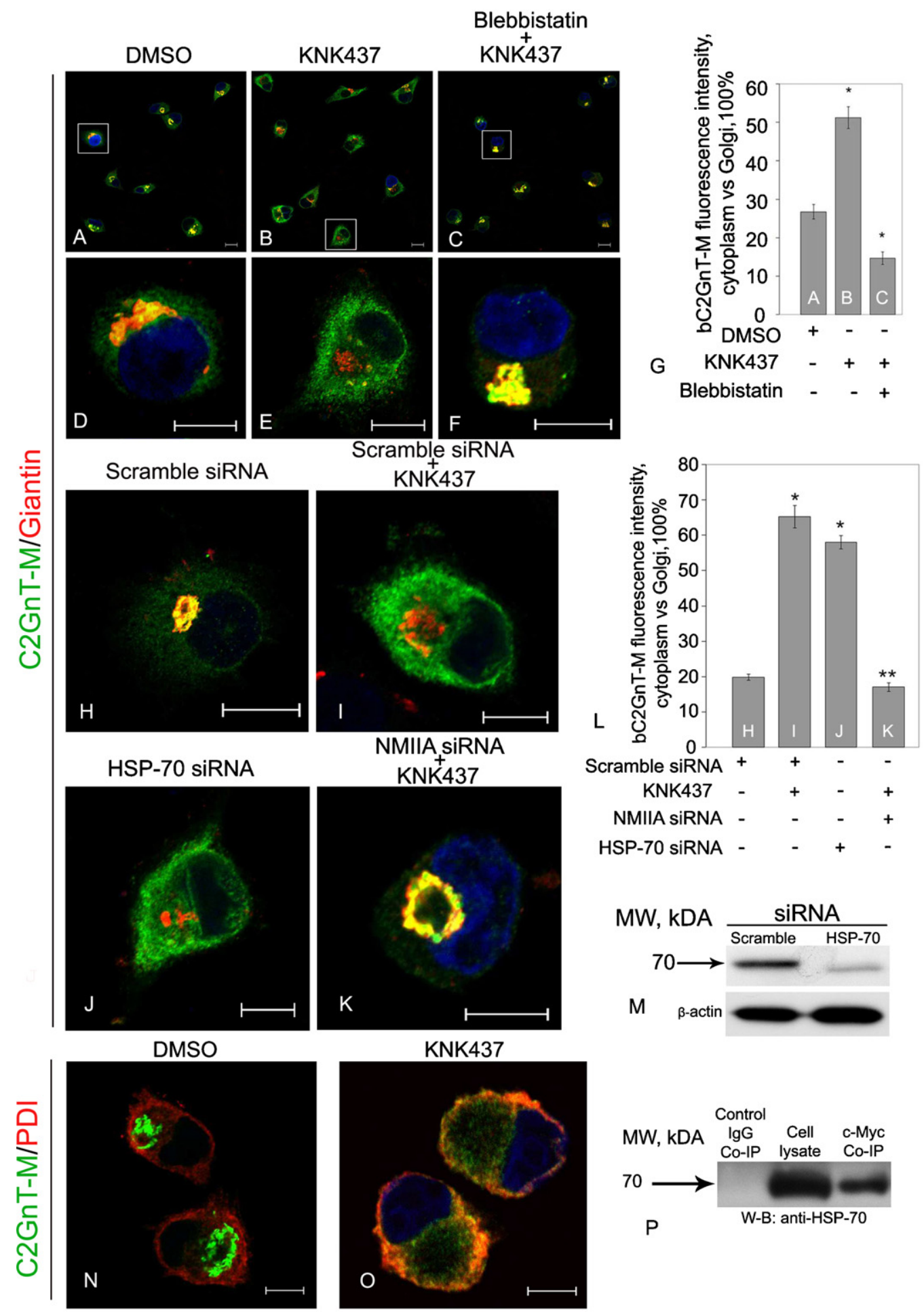

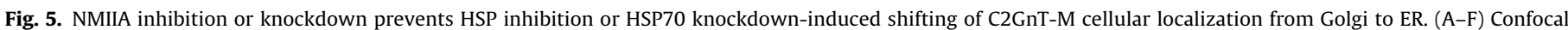

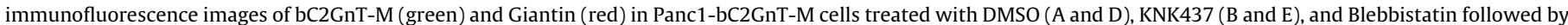

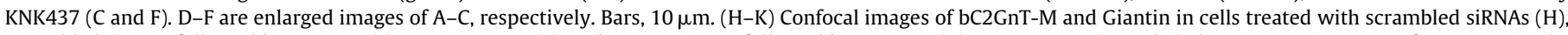

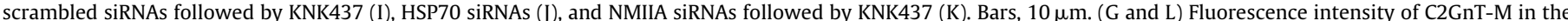

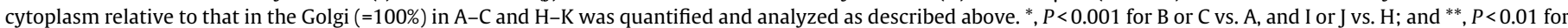

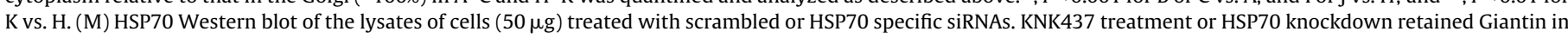

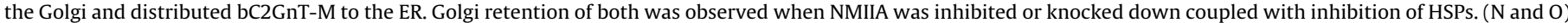

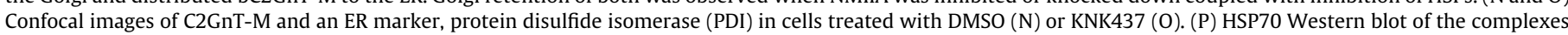

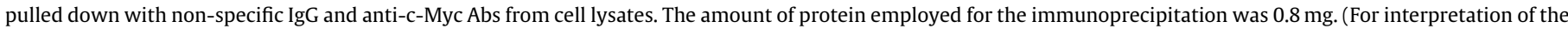
references to color in this figure legend, the reader is referred to the web version of the article.) 

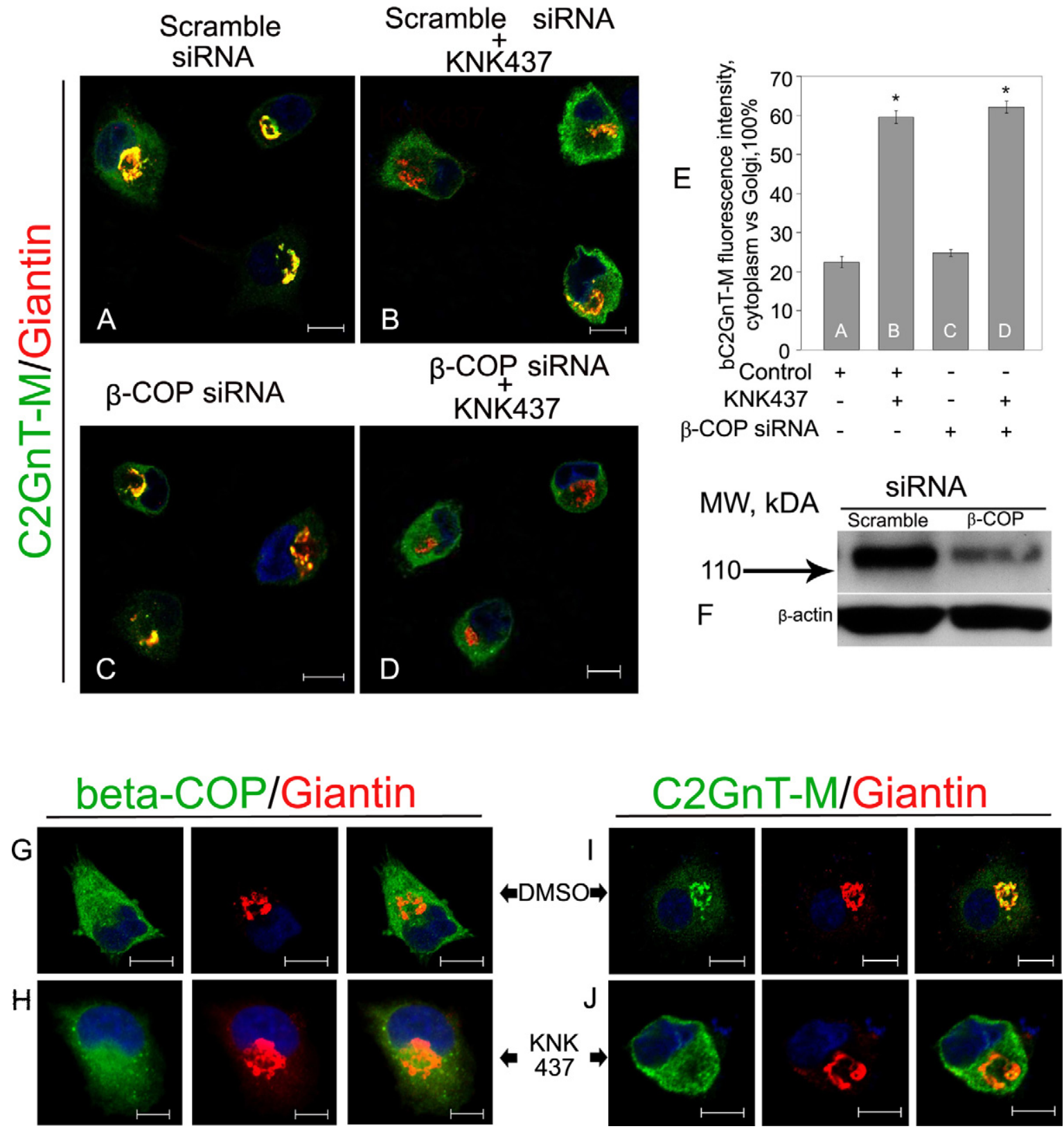

Fig. 6. $\beta$-COP knockdown does not affect intracellular distribution of C2GnT-M in Panc1-bC2GnT-M (c-Myc) cells with or without treatment with KNK437. (A-D) Confocal images of bC2GnT-M and Giantin in cells treated with scrambled siRNAs (A), scrambled siRNAs followed by KNK437 (B), $\beta$-COP siRNAs (C), and $\beta$-COP siRNAs followed by KNK437 (D). Bars, $10 \mu \mathrm{m}$. (E) Quantification of the C2GnT-M fluorescence signal in the cytosolic compartment relative to that of the Golgi (=100\%). The analysis was performed on the complete confocal stacks of 50 cells from three independent experiments. Data are expressed as mean percentage \pm SEM $*, P<0.001$ for B vs. A, and D vs. C. The bC2GnT-M distribution was not affected after $\beta$-COP knockdown. KNK437 treatment has distributed bC2GnT-M to the ER even in the $\beta$-COP deficiency. (F) $\beta$-COP Western blot of the lysates of cells $(50 \mu \mathrm{g})$ treated with scrambled or $\beta$-COP-specific siRNAs. (G-J) Confocal images of $\beta$-COP and Giantin or C2GnT-M and Giantin in cells treated with DMSO or KNK437. Note that in control (G), $\beta$-COP distributes throughout the cell, but locates primarily in the Golgi area after KNK treatment (H). Unlike $\beta$-COP, C2GnT-M moves away from the Golgi following KNK437 treatment (I and J).

by proteasome. Interestingly, MG-132 treatment also increased NMIIA (Fig. 7F and G), suggesting that NMIIA was also degraded by proteasome.

\section{Discussion}

The cytoplasmic tails of Golgi glycosyltransferases have been shown to be involved in the ER-to-Golgi transport (Giraudo and Maccioni, 2003; Watanabe and Riezman, 2004; Guo et al., 2008) and Golgi retention (Burke et al., 1994; Grabenhorst and Conradt, 1999; Uliana et al., 2006) of these enzymes. In this study, we have expanded the functional role of the cytoplasmic tails of glycosyltransferases by showing that they also are involved in the Golgi-to-ER transport of these enzymes by binding to NMIIA. This NMIIA-mediated process is likely involved in Golgi remodeling.

We have found that NMIIA directly binds to C2GnT-M through the C-terminal 1682-1960 aa region of NMIIA heavy chain and the 4-6aa of the cytoplasmic tail of C2GnT-M. The co-localization of C2GnT-M with NMIIA at the periphery of the Golgi coupled with the observation that a significant amount, i.e. $43 \%$, of C2GnT-M is not pulled down with anti-NMIIA Abs (Fig. 1C) suggests that there is another pool of C2GnT-M that does not bind to NMIIA. The protein that binds to this pool of C2GnT-M is likely involved in the Golgi retention of this enzyme and it remains to be identified. In 


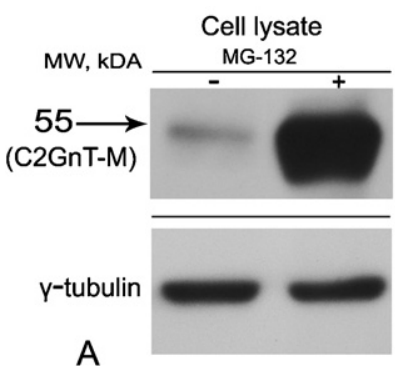

A

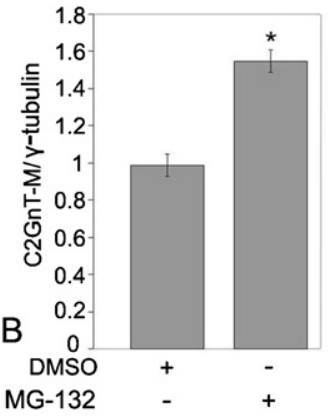

MG-132

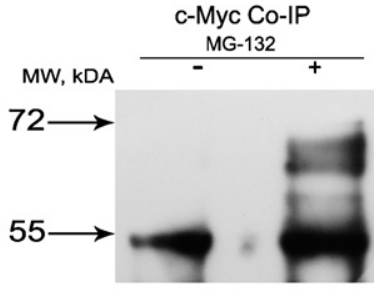

C
W-B: anti-Ubiquitin
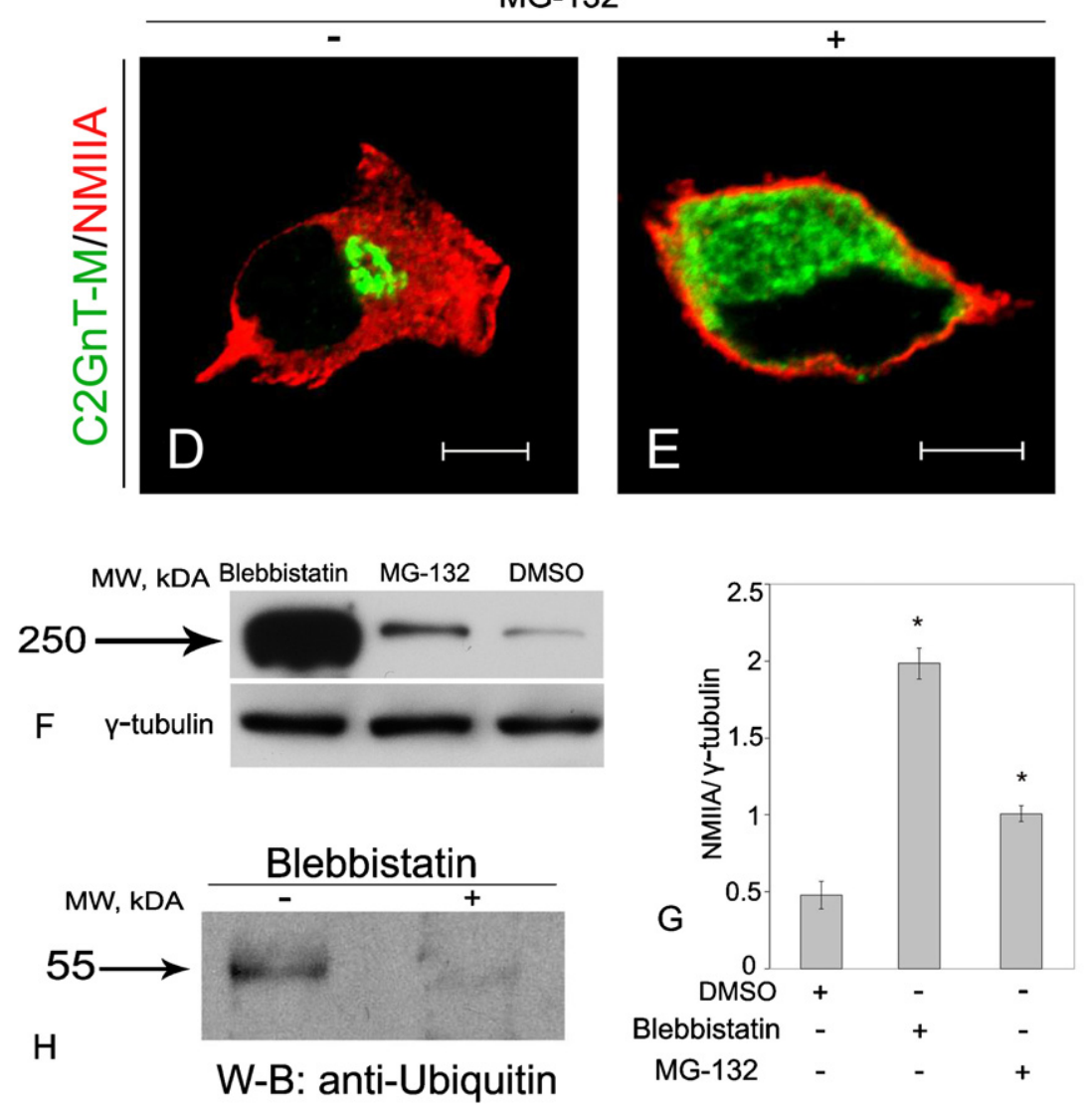

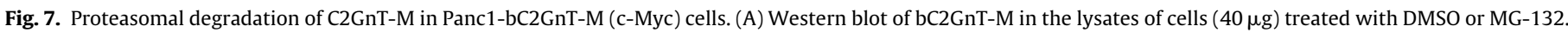

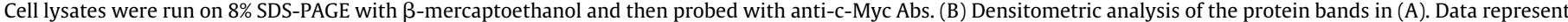

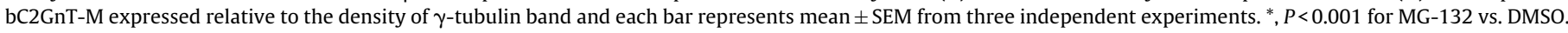

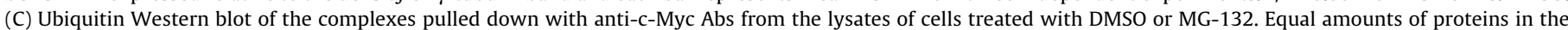

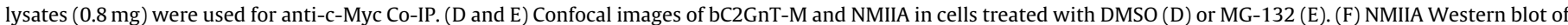

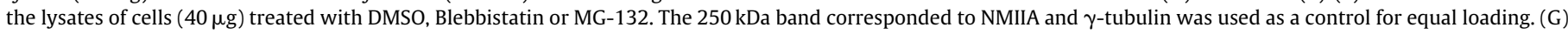

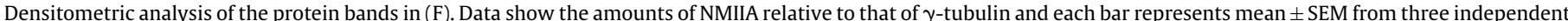

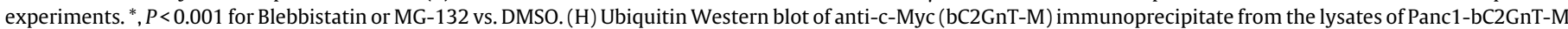

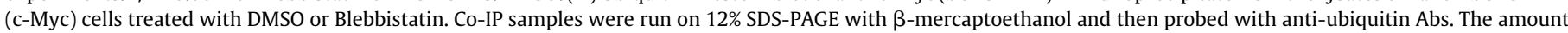
of protein employed for the immunoprecipitation for both lane was $0.7 \mathrm{mg}$.

addition, our data suggest that NMIIA is involved in the Golgi-to-ER transport of not only C2GnT-M but also many other Golgi proteins because inhibition of NMIIA prevents the BFA-induced collapse of the Golgi, and the exit of many Golgi proteins including C2GnT-M but not Giantin when HSPs are inhibited or HSP70 is depleted. In addition, the NMIIA-mediated Golgi-to-ER transport of C2GnT-M is independent of COPI because knockdown of $\beta$-COP does not affect the distribution of C2GnT-M under basal or KNK437 treatment condition. Also, inhibition of NMIIA does not change $\beta$-COP distribution, and KNK437 treatment leaves $\beta$-COP concentrated around the Golgi. We conclude that C2GnT-M is transported from the Golgi to the ER in a COPI-independent process which is in good agreement with several other reports showing an alternative route to COPI retrograde transport of glycosyltransferases (Girod et al., 1999; Jiang and Storrie, 2005; Lee et al., 2004; Storrie et al., 2000) but at variance with one recent report which claims the involvement of COPI in the Golgi-to-ER transport of peptidyl GalNAc transferases (Gill et al., 2010). However, we still do not know if COPI vesicles are involved in the intra-Golgi transportation of C2GnT-M (Cosson et al., 2002; Guo et al., 2008; Love et al., 1998; Lanoix et al., 1999).

One major function of HSPs is to help protein folding in the ER and Golgi targeting (Velez-Granell et al., 1994). The 


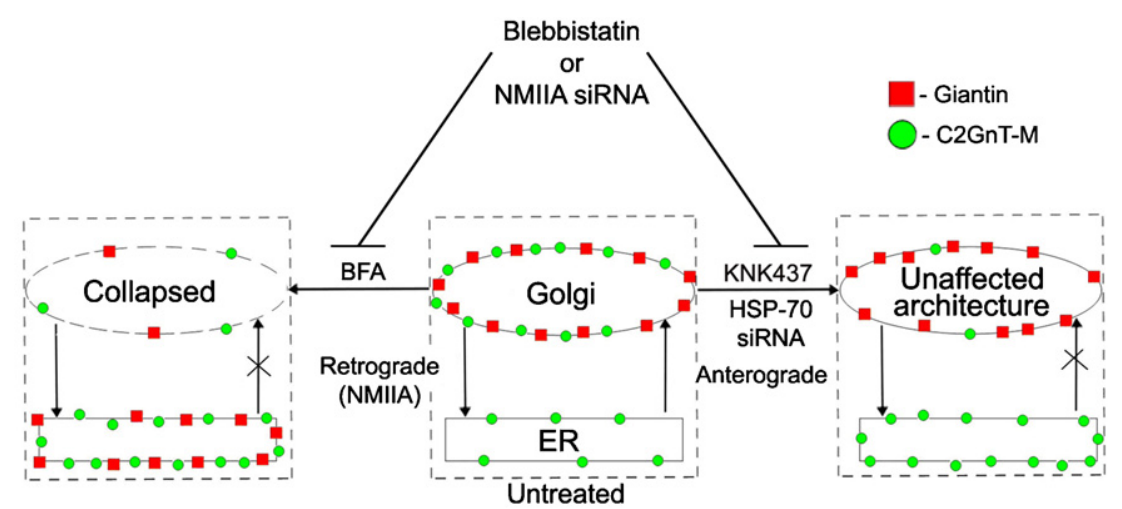

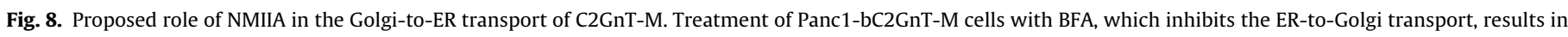

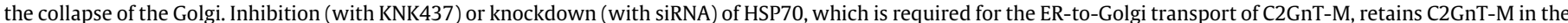

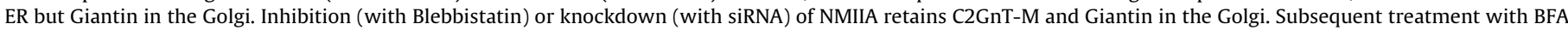

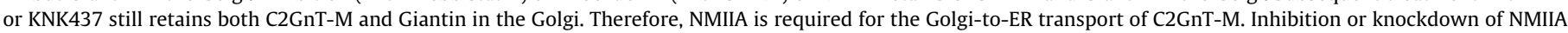

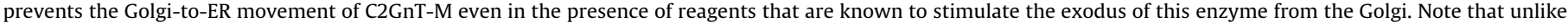
BFA, KNK437 does not alter the Golgi morphology.

improperly folded proteins are degraded by the ER-assisted protein degradation mechanism (Pfeffer and Rothman, 1987; Helenius et al., 1992; Arias and Bendayan, 1993). We have found that treatment of the cells with KNK437 results in retention of Giantin in the Golgi but accumulation of C2GnT-M in the ER. This outcome is likely resulted from the inhibition of its anterograde transport by KNK437 coupled with unimpeded trafficking of C2GnT-M from Golgi to ER mediated by NMIIA (Fig. 8). The results support the role of HSP70s in assisting the folding of C2GnT-M and subsequent trafficking to the Golgi (Walter and Buchner, 2002; Triantafilou and Triantafilou, 2004; Hartl and Hayer-Hartl, 2009). These data also confirm the concept that Golgi is made of two different membrane proteins, one is represented by Giantin of which Golgi retention is resistant to KNK437, and the other one is represented by C2GnT-M of which Golgi retention is sensitive to KNK437. This feature makes KNK437 a useful inhibitor for studying the Golgi-to-ER retrograde transport of glycosyltransferases because, unlike BFA, KNK437 does not affect the Golgi architecture (Fig. 8).

We have found that C2GnT-M is degraded by proteasome because MG-132 treatment results in accumulation of total as well as ubiquitinated bC2GnT-M. NMIIA is involved in this process because Blebbistatin treatment leads to accumulation of NMIIA but a reduction in ubiquitinated bC2GnT-M. The results suggest that the final destination of NMIIA-dependent Golgi-to-ER transport of $\mathrm{bC2} \mathrm{GnT}-\mathrm{M}$ is proteasome. This conclusion is supported by the close association of bC2GnT-M and ubiquitin activating enzyme E1 as shown by the pulldown of ubiquitin activating enzyme E1 by antic-Myc Abs. The accumulation of NMIIA in Panc1-bC2GnT-M cells treated with MG-132 suggests that NMIIA is also degraded by proteasome. This observation confirms a recent report showing NMIIA involvement in proteasome-dependent degradation (Valiya Veettil et al., 2010; Vazhappilly et al., 2010).

We have shown that our approach of using a biotinylated cytoplasmic tail of a glycosyltransferase as a bait to isolate its cytoplasmic binding partners is quite useful because it may be used as a high throughput approach for identifying the cytoplasmic proteins that form complexes with a glycosyltransferase via its tail. This should be quite useful for glycosyltransferases of which immunoprecipitable antibodies are not yet available and thus immuno-precipitation approach is not feasible.

Fig. 9 summarizes the results of this study. Following the synthesis of C2GnT-M in the ER, C2GnT-M acquires a proper conformation as assisted by HSP70s. This enzyme is then transported, presumably on microtubules (Mcllvain et al., 1993; Karecla and Kreis, 1992), to the Golgi, where it is retained by binding to a protein yet to be identified. The Golgi-to-ER retrograde transport of this enzyme, presumably on actin filaments (De Pina et al., 2007), is determined by its direct interaction with NMIIA via its cytoplasmic tail and the C-terminal region of NMIIA. COPI is not involved in this process. The enzyme along with NMIIA is then degraded by proteasome. Our

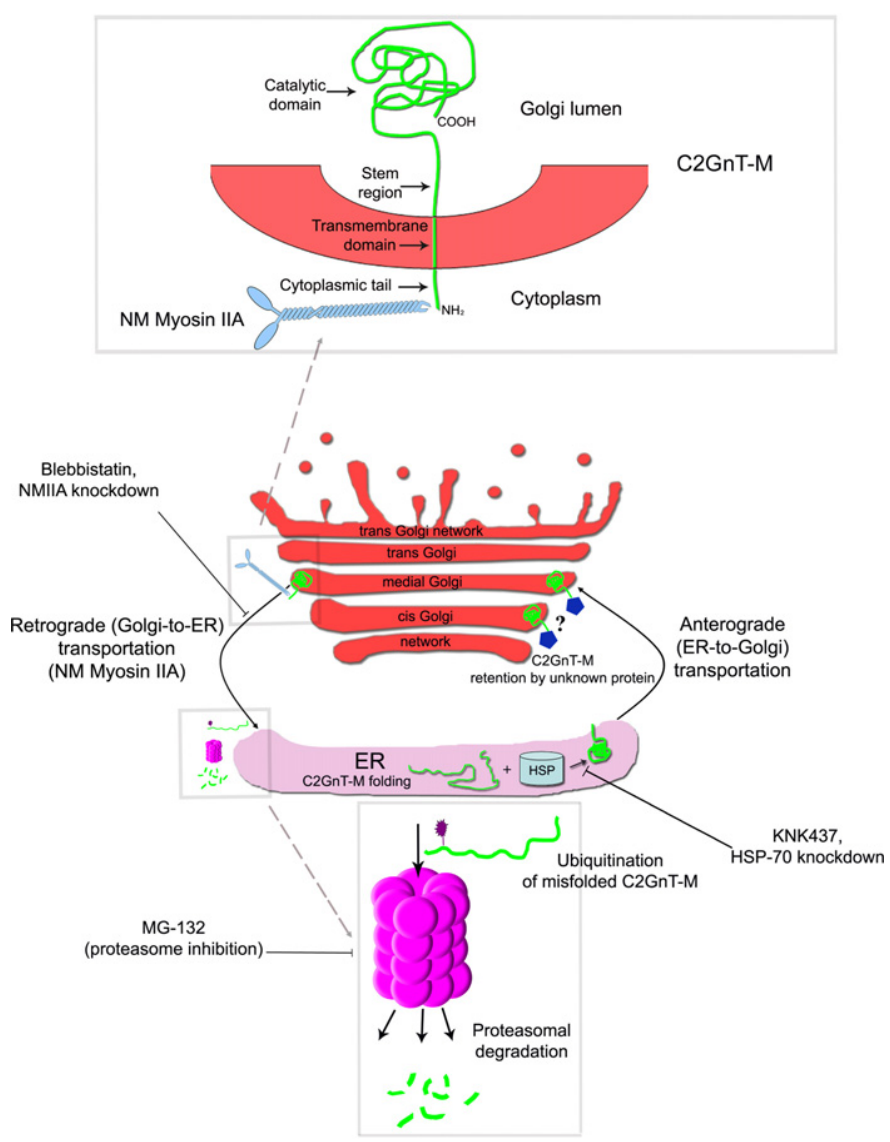

Fig. 9. Intracellular trafficking and distribution of C2GnT-M. C2GnT-M is synthesized in the ER, where HSP70 helps fold C2GnT-M properly, and then transported to the Golgi, where the enzyme is retained by binding to a protein yet to be identified. C2GnT-M returns to the ER in a NMIIA-dependent but COPI-independent process. This process is mediated by the interaction of the cytoplasmic tail (1-6 aa) of C2GnT$\mathrm{M}$ with the C-terminal portion (1682-1960 aa) of NMIIA heavy chain. C2GnT-M is degraded in the proteasome in a process mediated by ubiquitination. 
work has contributed to a better understanding of the intracellular trafficking of glycosyltransferases, specifically the involvement of NMIIA in the Golgi-to-ER transport of C2GnT-M. The work also suggests that NMIIA is involved in the Golgi remodeling.

\section{Acknowledgments}

The work is supported in part by the Office of Research and Development, Medical Research Service, Department of Veterans Affairs (VA 1I1BX000985), the NIH (1R21HL097238 and 2RO1HL48282) and the State of Nebraska (NRI-Cancer Glycobiology Program and LB506). We thank Dr. Sandra Wells for providing the human bronchial epithelium paraffin sections, Dr. David Smith for helpful discussion. We also thank the Mass Spectrometry and Proteomics Core Facility, and Janice A. Taylor and James R. Talaska of the Confocal Laser Scanning Microscope Core Facility at the University of Nebraska Medical Center for providing assistance in proteomics analysis and confocal microscopy, respectively, and the Nebraska Research Initiative and the Eppley Cancer Center for their support of the Core Facilities.

\section{References}

Ali SH, DeCaprio JA. Cellular transformation by SV40 large T antigen: interaction with host proteins. Seminars in Cancer Biology 2001;11(1):15-23.

Aoki D, Lee N, Yamaguchi N, Dubois C, Fukuda MN. Golgi retention of a transGolgi membrane protein, galactosyltransferase, requires cysteine and histidine residues within the membrane-anchoring domain. Proceedings of the National Academy of Sciences of the United States of America 1992;89(10):4319-23.

Appenzeller-Herzog C, Hauri HP. The ER-Golgi intermediate compartment (ERGIC): in search of its identity and function. Journal of Cell Science 2006;119(Pt 11):2173-83.

Arias AE, Bendayan M. Intracisternal crystals in pancreatic acinar cells: failure in the distinct aggregation of secretory proteins. European Journal of Cell Biology 1993;62(2):282-93.

Bray D. Cell movements. From molecules to motility. New York: Garland Publishing; 2001.

Burgess TL, Skoufias DA, Wilson L. Disruption of the Golgi apparatus with brefeldin A does not destabilize the associated detyrosinated microtubule network. Cell Motility and the Cytoskeleton 1991;20(4):289-300.

Burke J, Pettitt JM, Humphris D, Gleeson PA. Medial-Golgi retention of Nacetylglucosaminyltransferase I. Contribution from all domains of the enzyme. Journal of Biological Chemistry 1994;269(16):12049-59.

Chan W, Calderon G, Swift AL, Moseley J, Li S, Hosoya H, et al. Myosin II regulatory light chain is required for trafficking of bile salt export protein to the apical membrane in Madin-Darby canine kidney cells. Journal of Biological Chemistry 2005;280(25):23741-7.

Cheng P-W, Radhakrishnan P. Mucin glycan branching enzymes: structure, function and gene regulation. In: Wu A, editor. Molecular immunology of complex carbohydrates-3. Advances in Experimental Medicine and Biology, vol. 705. New York, N.Y.: Plenum Press; 2011. p. 465-92.

Choi KH, Basma H, Singh J, Cheng PW. Activation of CMV promoter-controlled glycosyltransferase and beta-galactosidase glycogenes by butyrate, tricostatin $\mathrm{A}$ and 5-aza-2'-deoxycytidine. Glycoconjugate Journal 2005;22(1-2):63-9.

Colley KJ. Golgi localization of glycosyltransferases: more questions than answers. Glycobiology 1997;7(1):1-13.

Conti MA, Adelstein RS. Nonmuscle myosin II moves in new directions. Journal of Cell Science 2008;121(Pt 1):11-8.

Cosson P, Amherdt M, Rothman JE, Orci L. A resident Golgi protein is excluded from peri-Golgi vesicles in NRK cells. Proceedings of the National Academy of Sciences of the United States of America 2002;99(20):12831-4.

De Pina AS, Wöllert T, Langford GM. Membrane associated nonmuscle myosin II functions as a motor for actin-based vesicle transport in clam oocyte extracts. Cell Motility and the Cytoskeleton 2007;64(10):739-55.

Donaldson JG, Lippincott-Schwartz J, Bloom GS, Kreis TE, Klausner RD. Dissociation of a $110-\mathrm{kD}$ peripheral membrane protein from the Golgi apparatus is an early event in brefeldin A action. Journal of Cell Biology 1990;111(6 Pt 1):2295-306.

Duran JM, Valderrama F, Castel S, Magdalena J, Tomas M, Hosoya H, et al. Myosin motors and not actin comets are mediators of the actin-based Golgito-endoplasmic reticulum protein transport. Molecular Biology of the Cell 2003;14(2):445-59.

El-Battari A. Autofluorescent proteins for monitoring the intracellular distribution of glycosyltransferases. Methods in Enzymology 2006;416:102-20.

Fath KR. Characterization of myosin-II binding to Golgi stacks in vitro. Cell Motility and the Cytoskeleton 2005;60(4):222-35.

Gill DJ, Chia J, Senewiratne J, Bard F. Regulation of O-glycosylation through Golgi-toER relocation of initiation enzymes. Journal of Cell Biology 2010;189(5):843-58.
Giraudo CG, Maccioni HJ. Endoplasmic reticulum export of glycosyltransferases depends on interaction of a cytoplasmic dibasic motif with Sar1. Molecular Biology of the Cell 2003;14(9):3753-66.

Girod A, Storrie B, Simpson JC, Johannes L, Goud B, Roberts LM, et al. Evidence for a COP-I-independent transport route from the Golgi complex to the endoplasmic reticulum. Nature Cell Biology 1999;1(7):423-30.

Grabenhorst E, Conradt HS. The cytoplasmic, transmembrane, and stem regions of glycosyltransferases specify their in vivo functional sublocalization and stability in the Golgi. Journal of Biological Chemistry 1999;274(51):36107-16.

Guo Y, Linstedt AD. COPII-Golgi protein interactions regulate COPII coat assembly and Golgi size. Journal of Cell Biology 2006;174(1):53-63.

Guo Y, Punj V, Sengupta D, Linstedt AD. Coat-tether interaction in Golgi organization. Molecular Biology of the Cell 2008;19(7):2830-43

Hartl FU, Hayer-Hartl M. Converging concepts of protein folding in vitro and in vivo. Nature Structural \& Molecular Biology 2009;16(6):57-81.

Helenius A, Marquardt T, Braakman I. The endoplasmic reticulum as a proteinfolding compartment. Trends in Cell Biology 1992;2(8):227-31.

Helms JB, Rothman JE. Inhibition by brefeldin A of a Golgi membrane enzyme that catalyses exchange of guanine nucleotide bound to ARF. Nature 1992;360(6402):352-4.

Ivessa NE, De Lemos-Chiarandini C, Gravotta D, Sabatini DD, Kreibich G. The Brefeldin A-induced retrograde transport from the Golgi apparatus to the endoplasmic reticulum depends on calcium sequestered to intracellular stores. Journal of Biological Chemistry 1995;270(43):25960-7.

Jiang S, Storrie B. Cisternal rab proteins regulate Golgi apparatus redistribution in response to hypotonic stress. Molecular Biology of the Cell 2005;16(5):2586-96.

Karecla PI, Kreis TE. Interaction of membranes of the Golgi complex with microtubules in vitro. European Journal of Cell Biology 1992;57(2):139-46.

King SM. The dynein microtubule motor. Biochimica et Biophysica Acta 2000;1496(1):60-75.

Kovács M, Tóth J, Hetényi C, Málnási-Csizmadia A, Sellers JR. Mechanism of blebbistatin inhibition of myosin II. Journal of Biological Chemistry 2004;279(34):35557-63.

Lanoix J, Ouwendijk J, Lin CC, Stark A, Love HD, Ostermann J, et al. GTP hydrolysis by arf-mediates sorting and concentration of Golgi resident enzymes into functional COP I vesicles. EMBO Journal 1999;18(18):4935-48.

Lee C, Goldberg J. Structure of coatomer cage proteins and the relationship among COPI, COPII, and clathrin vesicle coats. Cell 2010;142(1):123-32.

Lee MC, Miller EA, Goldberg J, Orci L, Schekman R. Bi-directional protein transport between the ER and Golgi. Annual Review of Cell and Developmental Biology 2004;20:87-123.

Lippincott-Schwartz J. Membrane cycling between the ER and Golgi apparatus and its role in biosynthetic transport. Sub-Cellular Biochemistry 1993;21:95-119.

Leu JI, Pimkina J, Frank A, Murphy ME, George DL. A small molecule inhibitor of inducible heat shock protein 70. Molecular Cell 2009;36:15-27.

Love HD, Lin CC, Short CS, Ostermann J. Isolation of functional Golgi-derived vesicles with a possible role in retrograde transport. Journal of Cell Biology 1998;140(3):541-51.

Ludowyke RI, Elgundi Z, Kranenburg T, Stehn JR, Schmitz-Peiffer C, Hughes WE, et al. Phosphorylation of nonmuscle myosin heavy chain IIA on Ser1917 is mediated by protein kinase $C$ beta II and coincides with the onset of stimulated degranulation of RBL-2H3 mast cells. Journal of Immunology 2006;177(3):1492-9.

Marsh BJ, Howell KE. The mammalian Golgi-complex debates. Nature Reviews Molecular Cell Biology 2002;3(10):789-95.

McIlvain Jr JM, Lamb C, Dabora S, Sheetz MP. Microtubule motor-dependent formation of tubulovesicular networks from endoplasmic reticulum and Golgi membranes. Methods in Cell Biology 1993;39:227-36.

Munro S. The golgin coiled-coil proteins of the Golgi apparatus. Cold Spring Harbor Perspectives in Biology 2011;3(6), pii:a005256.

Nakamura N. Emerging new roles of GM130, a cis-Golgi matrix protein, in higher order cell functions. Journal of Pharmacological Sciences 2010;112(3): 255-64.

Nilsson T, Rabouille C, Hui N, Watson R, Warren G. The role of the membranespanning domain and stalk region of $\mathrm{N}$-acetylglucosaminyltransferase $\mathrm{I}$ in retention, kin recognition and structural maintenance of the Golgi apparatus in HeLa cells. Journal of Cell Science 1996;109(Pt 7):1975-89.

Okamoto M, Yoko-o T, Miyakawa T, Jigami Y. The cytoplasmic region of alpha-1,6 mannosyltransferase Mnn9p is crucial for retrograde transport from the Golg apparatus to the endoplasmic reticulum in Saccharomyces cerevisiae. Eukaryotic Cell 2008;7(2):310-8.

Osman N, McKenzie IF, Mouhtouris E, Sandrin MS. Switching aminoterminal cytoplasmic domains of alpha(1,2)fucosyltransferase and alpha $(1,3)$ galactosyltransferase alters the expression of $\mathrm{H}$ substance and Galalpha(1,3)Gal. Journal of Biological Chemistry 1996;271(51):33105-9.

Palmer KJ, Hughes H, Stephens DJ. Specificity of cytoplasmic dynein subunits in discrete membrane-trafficking steps. Molecular Biology of the Cell 2009;20(12):2885-99.

Pfeffer SR, Rothman JE. Biosynthetic protein transport and sorting by the endoplasmic reticulum and Golgi. Annual Review of Biochemistry 1987;56:829-52.

Presley JF, Cole NB, Schroer TA, Hirschberg K, Zaal KJ, Lippincott-Schwartz J. ER-toGolgi transport visualized in living cells. Nature 1997;389(6646):81-5.

Puri S, Linstedt AD. Capacity of the Golgi apparatus for biogenesis from the endoplasmic reticulum. Molecular Biology of the Cell 2003;14(12):5011-8.

Puri S, Telfer H, Velliste M, Murphy RF, Linstedt AD. Dispersal of Golgi matrix proteins during mitotic Golgi disassembly. Journal of Cell Science 2004;117(Pt 3): 451-6. 
Quintero CA, Valdez-Taubas J, Ferrari ML, Haedo SD, Maccioni HJ. Calsenilin and CALP interact with the cytoplasmic tail of UDP-Gal:GA2/GM2/GD2 beta-1,3galactosyltransferase. Biochemical Journal 2008;412(1):19-26.

Richards TA, Cavalier-Smith T. Myosin domain evolution and the primary divergence of eukaryotes. Nature 2005;436(7054):1113-8.

Ropp PA, Little MR, Cheng P-W. Mucin biosynthesis: purification and characterization of a mucin $\mathrm{N}$-acetylglucosaminyltransferase. Journal of Biological Chemistry 1991;266(35):23863-71.

Schaub BE, Berger B, Berger EG, Rohrer J. Transition of galactosyltransferase 1 from trans-Golgi cisterna to the trans-Golgi network is signal mediated. Molecular Biology of the Cell 2006;17(12):5153-62.

Schmitz KR, Liu J, Li S, Setty TG, Wood CS, Burd CG, et al. Golgi localization of glycosyltransferases requires a Vps74p oligomer. Developmental Cell 2008;14(4):523-34.

Schwientek T, Nomoto M, Levery SB, Merkx G, van Kessel AG, Bennett EP, et al. Control of O-glycan branch formation. Molecular cloning of human cDNA encoding a novel beta1,6-N-acetylglucosaminyltransferase forming core 2 and core 4 . Biological Chemistry 1999;274(8):4504-12.

Sellers JR. Myosins: a diverse superfamily. Biochimica et Biophysica Acta 2000;1496(1):3-22.

Storrie B, Pepperkok R, Nilsson T. Breaking the COPI monopoly on Golgi recycling. Trends in Cell Biology 2000;10(9):385-91.

Storrie B, White J, Röttger S, Stelzer EH, Suganuma T, Nilsson T. Recycling of Golgi-resident glycosyltransferases through the ER reveals a novel pathway and provides an explanation for nocodazole-induced Golgi scattering. Journal of Cell Biology 1998;143(6):1505-21.

Straight AF, Cheung A, Limouze J, Chen I, Westwood NJ, Sellers JR, et al. Dissecting temporal and spatial control of cytokinesis with a myosin II Inhibitor. Science 2003;299(5613):1743-7.

Triantafilou M, Triantafilou K. Heat-shock protein 70 and heat-shock protein 90 associate with Toll-like receptor 4 in response to bacterial lipopolysaccharide. Biochemical Society Transactions 2004;32(Pt 4):636-9.

Tu L, Banfield DK. Localization of Golgi-resident glycosyltransferases. Cellular and Molecular Life Sciences 2010;67(1):29-41.
Tu L, Tai WCS, Chen L, Banfield DK. Signal-mediated dynamic retention of glycosyltransferases in the Golgi. Science 2008;321(5887):404-7.

Uemura S, Yoshida S, Shishido F, Inokuchi J. The cytoplasmic tail of GM3 synthase defines its subcellular localization, stability, and in vivo activity. Molecular Biology of the Cell 2009;20(13):3088-100.

Uliana AS, Giraudo CG, Maccioni HJ. Cytoplasmic tails of SialT2 and GalNAcT impose their respective proximal and distal Golgi localization. Traffic 2006;7(5): 604-12.

Valiya Veettil M, Sadagopan S, Kerur N, Chakraborty S, Chandran B. Interaction of c-Cbl with myosin IIA regulates Bleb associated macropinocytosis of Kaposi's sarcoma-associated herpesvirus. PLoS Pathogens 2010;6(12): e1001238.

Vazhappilly R, Wee KS, Sucher NJ, Low CM. A non-muscle myosin II motor links NR1 to retrograde trafficking and proteasomal degradation in PC12 cells. Neurochemistry 2010;56(4):569-76.

Velez-Granell CS, Arias AE, Torres-Ruíz JA, Bendayan M. Molecular chaperones in pancreatic tissue: the presence of cpn10, cpn60 and hsp70 in distinct compartments along the secretory pathway of the acinar cells. Journal of Cell Science 1994;107(Pt 3):539-49.

Walter S, Buchner J. Molecular chaperones - cellular machines for protein folding. Angewandte Chemie International Ed In English 2002;41(7): 1098-113.

Wassler MJ, Foote CI, Gelman IH, Shur BD. Functional interaction between the SSeCKS scaffolding protein and the cytoplasmic domain of beta1,4-galactosyltransferase. Journal of Cell Science 2001;114(Pt 12): 2291-300.

Watanabe R, Riezman H. Differential ER exit in yeast and mammalian cells. Current Opinion in Cell Biology 2004;16:350-5.

Waters MG, Serafini T, Rothman JE. 'Coatomer': a cytosolic protein complex containing subunits of non-clathrin-coated Golgi transport vesicles. Nature 1991;349(6306):248-51.

Yeh JC, Ong E, Fukuda M. Molecular cloning and expression of a novel beta-1, 6-Nacetylglucosaminyltransferase that forms core 2, core 4, and I branches. Journal of Biological Chemistry 1999;274(5):3215-21. 